\title{
Quantitative Easing in Joseph's Egypt with Keynesian Producers
}

\author{
Jeffrey R. Campbell*
}

September 2016

\begin{abstract}
This paper considers monetary and fiscal policy when tangible assets can be created and stored after shocks that increase desired savings, like Joseph's biblical prophecy of seven fat years followed by seven lean years. The model's flexible-price allocation mimics Joseph's saving to smooth consumption. With nominal rigidities, monetary policy that eliminates liquidity traps leaves the economy vulnerable to confidence recessions with low consumption and investment. Josephean Quantitative Easing, a fiscal policy that purchases either obligations collateralized by reproducible tangible assets or the assets themselves, eliminates both liquidity traps and confidence recessions by putting a floor under future consumption. This requires no commitment to a timeinconsistent plan. In a small open economy, the monetary authority can implement Josephean Quantitative Easing with a sterilized currency-market intervention that accumulates foreign reserves. This can improve outcomes even if it leaves nominal exchange rates unchanged.
\end{abstract}

*Federal Reserve Bank of Chicago and CentER, Tilburg University

E-mail: jcampbell@frbchi.org.

I am very grateful to Gadi Barlevy, Bob Barsky, Marco Bassetto, Paco Buera, Charlie Evans, and Simon Gilchrist for many discussions on this topic; to Refet Gürkaynak and Zvi Hercowitz for their insightful conference discussions; and to seminar participants at UPF-CREI for enduring a very preliminary presentation of this paper. An anonymous referee wrote very helpful comments, and Jacob Weber provided expert research assistance. The views expressed are those of the author. They do not necessarily represent the views of the Federal Reserve Bank of Chicago, the Federal Reserve System, or its Board of Governors.

JEL Codes: E12, E63.

Keywords: Zero Lower Bound, Liquidity Trap, Confidence Recession, Storage, Equilibrium Multiplicity, Small Open Economy, Sterilized Currency Market Intervention. 
"Accordingly, let Pharaoh find a man of discernment and wisdom, and set him over the land of Egypt. And let Pharaoh take steps to appoint overseers over the land and organize the land of Egypt in the seven years of plenty. Let all the food of these good years that are coming be gathered, and let the grain be collected under Pharaoh's authority as food to be stored in the cities. Let that food be a reserve for the land for the seven years of famine which will come upon the land of Egypt, so that the land may not perish in the famine."

Genesis 41:33-36 in Berlin and Brettler (2004)

\section{Introduction}

This paper considers monetary and fiscal policy following unexpected increases of desired savings when tangible assets can be created and stored. Such increases of desired savings are the standard driving force in the modern theory of liquidity traps (Krugman, 1998; Eggertsson and Woodford, 2003), in which the zero lower bound makes monetary policy inappropriately tight and thereby sends the economy into recession. The story of Joseph prophetically forecasting seven fat years followed by seven lean years shares liquidity trap models' shock to desired savings, but the Bible records a superior macroeconomic outcome based on the accumulation of grain in the prosperous years which was drawn down during the following famine. Joseph achieved this using two advantages not available to liquidity-trap models' policy

makers. First, monetary frictions like sticky prices and the zero lower bound on interest rates presumably did not limit his policy options. Second, Joseph possessed a storage technology. In contrast, prominent liquidity trap models feature a fallacy of composition: Tangible assets cannot be accumulated, but individuals believe they can intertemporally substitute consumption using bonds. Since those models' liquidity traps arise when desired savings at potential output exceeds the supply of bonds, one might reasonably speculate that adding storage or another form of capital accumulation to the standard new Keynesian model can remove the threat of liquidity traps. Krugman (1998) addresses this possibility by arguing that adjustment costs make avoiding a liquidity trap using capital accumulation infeasible. Accordingly, Christiano, Eichenbaum, and Rebelo (2011) incorporate investment adjustment costs into their model of liquidity traps with capital accumulation. 
In this paper, I add a storage technology without adjustment costs to a New Keynesian model with nominal rigidities and then characterize the monetary and fiscal policies that can be used to avoid a recession and successfully accumulate assets during fat years for later consumption. The model's shock to desired savings qualitatively resembles the productivity sequence in the Joseph story, but it has one year of plenty and an infinite horizon of famine instead of the biblically specified seven years for each phase. The arrival of information that future productivity will fall (as in the story's dream sequence) is the supply-side analogue of the preference shock employed by Eggertsson and Woodford (2003) and Christiano, Eichenbaum, and Rebelo (2011) to lower the natural rate of interest. Together, price rigidities and elastically-supplied labor allow (but do not compel) the economy to fall into a recession (with output below its value in the unique flexible-price allocation) following this shock.

The original Joseph story featured literal storage prominently, and this can represent inventory accumulation in modern economies. However, the more empiricallyrelevant interpretations of the model's "storage" technology are investment in productive capital and the current account of a small open economy. I develop the details of the model's small open economy interpretation after the presentation of the main results. For expositional clarity, the model of the text embodies a linear storage technology. This abstracts from the decreasing returns typically associated with productive capital, so an appendix shows how to represent productive capital accumulation with a convex cost of storage and demonstrates that this paper's key results are robust to this modification. Since the Joseph story is familiar from both the Bible and Broadway, I use it throughout the paper as a mnemonic device and label all economy-wide wealth accumulation as "storage." As in the story, I use an anticipated technology shock to move the natural rate of interest. Demonstrating that the same results hold when technology is constant and instead a one-period discount-factor shock lowers the natural rate of interest is a straightforward exercise.

In a static version of the economy with some preset prices but without nominal bonds or storage; the economy has a continuum of distinct equilibrium allocations. A deflationary coordination game underlies this multiplicity: If firms with flexible prices believe that the present is deflationary, they choose low prices. This lowers both real aggregate consumption and marginal cost and thereby confirms their beliefs. This is the foundation of the model's Phillips curve. 
When there is no storage, households' optimal bond purchases resolve the Phillipscurve indeterminacy: the Euler equation determines the level of current consumption given a fixed real interest rate and the rational anticipation that consumption will equal its flexible-price level when the shock to desired savings has passed. With storage, future consumption is a free variable. This allows the static coordination game's multiplicity to manifest itself in a dynamic setting. Because storage bounds the real interest rate from below, it cannot be lowered any further to lift the economy out of such a recession.

The model's dynamic multiplicity implies that avoiding a recession in the economy's initial fat year might require a policy to raise current savings and thereby increase future consumption. Both Eggertsson and Woodford (2003) and Werning (2012) advocate lifting expectations of future consumption by committing to low future interest rates which lead consumption to overshoot its long-run level. A policy maker that exchanges nominal bonds for loans backed by storage achieves the same goal. Of course, these government bonds are net wealth (Barro, 1974), because they are backed by real assets. Since the storage technology is freely available, no individual household cares whether it undertakes storage directly or has the government do so on its behalf. However, the expansion of the government's balance sheet can influence aggregate outcomes by destroying otherwise possible recessionary equilibria: The natural non-negativity constraint on storage prevents households from offsetting the the government's real wealth accumulation, so debt-financed government savings raises the minimum possible national wealth in any equilibrium. After the shock to desired savings has passed, unwinding the monetary authority's position increases consumption; and the rational expectation of this raises the minimum possible consumption and output when the propensity to save is still high. Significantly, implementing this policy requires no commitment to a time-inconsistent plan.

Although this government savings policy accumulates real assets instead of government bonds, it seems reasonable to label this balance-sheet expansion a form of quantitative easing. Instead of increasing "aggregate demand," it potentially removes recessionary outcomes by shrinking the equilibrium set. The liabilities on Pharoh's balance sheet offsetting Joseph's accumulation of grain went unrecorded, but one might reasonably consider that policy to be a prototype for this form of quantitative easing. Hence, I label it Josephean. Since most major central banks' quantitative easing has focused on the purchase of sovereign debt, it would be 
ridiculous to assert that recent unconventional monetary policy heavily utilizes such Josephean quantitative easing (JQE). This paper has the more modest goals of delineating the obstacles to efficient intertemporal substitution that are inherent in New Keynesian models (particularly when facing the zero lower bound) and specifying monetary and fiscal policies that can overcome them.

Unlike the closed economies of many liquidity trap models, small open economies can intertemporally substitute consumption by running a current account surplus, investing the proceeds abroad, and repatriating them in the future. Krugman (1998) dismissed the possibility that such trade-facilitated intertemporal substitution could lift an economy out of a liquidity trap based on an analysis that takes the shortcut (his word) "that one can ignore the effect of the current account on the future investment income of the country." ${ }^{1}$ This paper's international interpretation shows that accounting for the country's future investment income is crucial for designing appropriate policy in a liquidity trap. In an international context, a sterilized intervention in foreign currency markets can implement JQE. The monetary authority issues liabilities in domestic currency and uses the proceeds to accumulate foreign assets. However, JQE does not operate through the real exchange rate. Instead, it (possibly) improves outcomes by putting a floor on expectations of future domestic consumption, just as it does in a closed economy. The foreign country experiences a current account deficit that reverses itself when the possibility of a liquidity trap has passed in the home country. Such unstable international capital flows are not an undesirable side effect of JQE; they are its goal.

Although early models of liquidity traps featured a fallacy of composition, recently Correia, Farhi, Nicolini, and Teles (2013) and Christiano, Eichenbaum, and Rebelo (2011) have examined them in models with capital accumulation. Indeed, this paper's model is nearly a special case of that in Correia, Farhi, Nicolini, and Teles (2013). Those authors characterize the Pigouvian taxes that allow a competitive equilibrium to coincide with the optimal allocation. This paper complements theirs by showing how policy can make the flexible-price allocation the unique equilibrium using JQE. (Since firms' markups might be part of a preexisting scheme that grants monopoly rights to induce innovation, I consider only the modest goal of implementing the flexible-price allocation instead of the more ambitious aspiration of achieving a completely distortion-free allocation.)

\footnotetext{
${ }^{1}$ See (Krugman, 1998, Page 164).
} 
Christiano, Eichenbaum, and Rebelo (2011) quantitatively examined the government spending multiplier under the common assumptions that an interest-rate rule satisfying the Taylor principle governs the nominal interest rate (subject to the zero-lower-bound) and that equilibrium sequences converge to the unique steady state with active monetary policy (Benhabib, Schmitt-Grohé, and Uribe, 2001). In the present model, such an imposition of local determinacy indeed eliminates equilibrium multiplicity. When the interest-rate rule and its inflation target are appropriately chosen, the unique equilibrium implements the flexible-price allocation. However, this criterion eliminates a continuum of other less desirable equilibria merely because they induce the monetary authority to drive the economy into the zero lower bound permanently. Aruoba, Cuba-Borda, and Schorfheide (2016) document that such a equilibrium replicates the Japanese experience since 1995 well. Furthermore, neither market-clearing nor individual optimality requires inflation to equal the monetary authority's target in the long run (Cochrane, 2011). Therefore there are neither theoretical nor general empirical grounds for removing such outcomes from consideration ex-ante. I show that an appropriate choice of JQE can remove them from the equilibrium set ex-post.

Previous work on fiscal policy in liquidity traps has focused on purchasing public goods that impact neither the marginal utility of private consumption nor production possibilities. Eggertsson (2011) and Christiano, Eichenbaum, and Rebelo (2011) argue that the multiplier effects of such government spending are large in liquidity traps caused by shocks to desired savings, because the usual crowding out of investment by debt-financed government spending disappears when the nominal interest rate is stuck at the zero lower bound. Erceg and Lindé (2014) temper this conclusion by demonstrating that the marginal government-spending multiplier can sharply fall if fiscal expansion actually shortens the liquidity trap, and Mertens and Ravn (2014) show that the government-spending multiplier is lower than usual in liquidity traps caused by a self-fulfilling state of low confidence. This paper also casts doubt on the usefulness of increasing "useless" government spending in a liquidity trap. When there are real opportunities to accumulate national wealth, debt-financed government spending that decreases the marginal utility of future private consumption can guide the economy to the flexible-price outcome. That is, fear of falling into a liquidity trap following an increase in desired savings need not justify expanded purchases of public goods. Instead, it calls for the policy authority to save on be- 
half of households and thereby eliminate recessions driven by households' failure to coordinate on an equilibrium with both high consumption and high investment.

The shocks to desired savings in liquidity-trap models are usually interpreted as stand-ins for the balance-sheet repair that follows financial-market turmoil. Eggertsson and Krugman (2012) expand on this by explicitly modeling the financial turmoil as a "Fisher-Minsky-Koo" moment, in which a contraction of consumer credit and debt deflation reduce aggregate demand. Fornaro (2013) shows that consumer debt forgiveness then can be Pareto improving: Borrowers' consumption increases while savers' consumption remains the same. Relatedly Buera and Nicolini (2014) model a liquidity trap as resulting from a tightening of producers' borrowing constraints. Extending the present analysis to determine the potential of unconventional policy to mitigate such liquidity traps (holding fixed the dysfunctional credit markets) by encouraging real wealth accumulation lies beyond this paper's scope.

The remainder of this paper proceeds as follows. The next section contains the model's primitive assumptions, and Section 3 presents its flexible-price allocation. Section 4 adds nominal rigidities and characterizes the resulting recessionary equilibria. These can usefully be divided into two classes, liquidity traps and confidence recessions. In liquidity traps, monetary policy is so tight that bonds' real return dominates that of the storage technology; whereas in confidence recessions the returns to bonds and storage equal one another but self-fulfilling expectations of low future consumption cause low current consumption. Section 5 shows how JQE can destroy these equilibria, and it places this paper's results in the context of previous theoretical characterizations of QE. Section 6 develops the interpretation of the

model as a small open economy that stores consumption by trading the aggregate good with a large foreign sector. Section 7 offers concluding remarks that discuss the political difficulties of "choosing winners" when accumulating private domesticallyissued assets and interpret the Bank of Israel's recent sterilized foreign exchange interventions through the lens of the model.

\section{Primitive Assumptions}

The model features three key features of New Keynesian economies, monopolistic competition so that goods' prices are set by specific agents, nominal rigidities which generate a Phillips curve trading off inflation and output, and a market for nominal 
bonds with an interest rate set by a policy authority subject to the zero lower bound. Additionally, the policy authority can issue nominal bonds and invest the proceeds within the storage technology. This access to a technology for intertemporal transformation of goods does not distinguish the policy authority from the economy's households. Henceforth I anthropomorphize this authority and name him "Joseph".

The presentation of the model's primitive assumptions follows the conventional preferences-technology-trading opportunities road map. A single representative household populates the model economy. Its preferences over streams of consumption goods and time spent at work are

$$
U\left(\left\{C_{t}\right\},\left\{N_{t}\right\}\right)=\sum_{t=0}^{\infty} \beta^{t}\left(\ln C_{t}-\theta N_{t}\right)
$$

Here $N_{t}$ is time spent at work and $C_{t}$ is consumption of the aggregate good. It is well-known that quasi-linear preferences like these feature an infinite Frisch elasticity of labor supply. Following Auerbach and Obstfeld (2005), I adopt them here for algebraic convenience. Since there is no extrinsic uncertainty in this economy and I restrict attention to deterministic equilibria, risk-aversion plays no role in this analysis. I (implicitly) set the elasticity of intertemporal substitution to one only to avoid unnecessary parameter proliferation.

Without storage, the natural non-negativity constraint on time at work would be irrelevant because the marginal rate of substitution between consumption and leisure grows without bound as consumption goes to zero. Since storage creates the possibility of consumption without work, I make this constraint explicit with

$$
N_{t} \geq 0
$$

Replacing (1) with a positive lower bound on hours worked, which is perhaps more realistic, would leave this paper's results unchanged.

Households produce the aggregate good by assembling differentiated goods with a CES production technology.

$$
Y_{t} \equiv\left(\int_{0}^{1} Y_{t}(j)^{\frac{\varepsilon-1}{\varepsilon}} d j\right)^{\frac{\varepsilon}{\varepsilon-1}}
$$

Here, $Y_{t}(j)$ is the input of good $j$ (with $j \in[0,1]$ ) in year $t$, and $\varepsilon>1$ is the elasticity 
of substitution between any two of the differentiated goods. ${ }^{2}$ The technology for producing each of the differentiated goods is the same: one unit of labor yields $A_{t}$ units of the good in question. To make a liquidity trap possible, I assume that $A_{0}=A^{H}$ and $A_{t}=A^{L}<A^{H}$ for all $t \geq 1$.

The economy's other technology is that for storage. To have $S$ units of the aggregate good available next year, one must invest $S /(1-\delta)$ units of the aggregate good today. Here, $\delta$ is the depreciation rate on storage. So that this technology cannot be used to transfer resources from the future into the present, I require

$$
S_{t} \geq 0
$$

In the model's interpretation as a small open economy, (2) becomes a constraint on borrowing from abroad. Although it is natural to assume that $\delta \geq 0$, the analysis below only requires

$$
1>\beta^{2}(1-\delta)^{2} \frac{A^{H}}{A^{L}} .
$$

This more generous bound on $\delta$ will be helpful when interpreting "storage" as investment abroad with a positive real return. At the cost of complicating the analysis, (3) could be relaxed to the weaker condition that $1>\beta(1-\delta)$, which ensures that the storage technology is not used when the consumption sequence is constant. The benefit of this stronger condition will become apparent below when I use it to ensure that the storage technology is never employed after year 0 .

Trade occurs in a labor market, product markets, and financial markets. The labor market is perfectly competitive with nominal wage $W_{t}$. Product markets conform to the familiar monopolistic competition framework. Each product's monopolist chooses its nominal price taking as given all other products' prices, aggregate income, and the household's demand system for all of the differentiated products. The function $P_{t}(j)$ gives the monopolists' nominal prices in year $t$.

The model's nominal rigidity resembles Fisher's (1977) model of overlapping labor contracts. Each year, half of the economy's producers set their nominal prices for the current and next years; and these two nominal prices need not equal each other. By eliminating intertemporal trade-offs in price setting inherent in the more commonly employed Calvo (1983) specification, I focus the analysis on intertemporal

\footnotetext{
${ }^{2}$ For simplicity only, I leave the operation of the constant-returns-to-scale assembly technology with the household.
} 
substitution and the obstacles to its efficient execution.

Joseph sets the interest rate for nominal bonds purchased in $t$ that mature in $t+1$ subject to the zero lower bound after observing storage brought into the year $S_{t}$, the nominal wage $W_{t}$, producers' price choices and real outputs $P_{t}(\cdot)$ and $Y_{t}(\cdot)$, and households' consumption $C_{t}$. Joseph collects this information, the rationally anticipated path for $A_{t}$, and the complete histories of consumption, storage, and nominal wages and prices through year $t-1$ into the information set $\Omega_{t}$ and inputs it into the interest rate rule $i_{t}=\rho\left(\Omega_{t}\right)$. Joseph selects this rule at the beginning of time and thereafter follows its prescriptions absolutely. Wicksellian models (like this one) place the zero lower bound in the monetary policy rule as a stand-in for the analogous no-arbitrage condition that would come out of an explicit specification for money demand. Accordingly, I henceforth require $\rho\left(\Omega_{t}\right) \geq 0$ for all possible $\Omega_{t}$.

To undertake JQE, Joseph issues nominal bonds, uses the proceeds to acquire the aggregate good from households, and directly invests the goods acquired in the storage technology. It is the restriction to investing in assets that contribute to real national wealth that distinguishes JQE from general quantitative easing, not the direct use of the storage technology per se. (The appendix extends the model to have Joseph invest in privately-issued assets backed by stored goods. This modification changes no result.) Let $Q_{t+1}$ denote the amount of the aggregate good available in $t+1$ from Joseph's storage investments during $t$, and use $B_{t+1}$ to represent the nominal redemption value of the bonds Joseph issued in $t$ to finance that storage. In contrast with the Pigouvian policy maker in Correia, Farhi, Nicolini, and Teles (2013), Joseph has access to no other tax instruments. Therefore, given $Q_{0}=B_{0}=0$, the sequences $Q_{t}$ and $B_{t}$ must satisfy the feasibility constraint

$$
Q_{t+1}=(1-\delta)\left(\left(\frac{B_{t+1}}{1+i_{t}}-B_{t}\right) / P_{t}+Q_{t}\right) .
$$

The storage technology and bond market are the only two mechanisms for individual households to effect intertemporal substitution. The model's analysis would be unchanged if it also included another store of value, such as land, which is in fixed supply and traded competitively. This is because such an asset cannot be used to increase national wealth and thereby influence future consumption. 


\section{The Flexible-Price Allocation}

The equilibrium allocation when producers face no nominal rigidities serves as a baseline for the subsequent analysis. Whether the household or the government undertakes storage is a matter of complete indifference when prices are flexible, so I assume for this section that $Q_{t+1}=B_{t+1}=0$ for all $t \geq 0$.

Begin the construction of a flexible-price equilibrium with the household's purchases of differentiated goods, which has the familiar form:

$$
Y_{t}(j)=Y_{t}\left(\frac{P_{t}(j)}{P_{t}}\right)^{-\varepsilon}
$$

with aggregate price index $P_{t} \equiv\left(\int_{0}^{1} P_{t}(j)^{1-\varepsilon}\right)^{\frac{1}{1-\varepsilon}} d j$. By construction, $P_{t} Y_{t}$ is the household's total nominal expenditure on goods. In a flexible-price equilibrium, each producer of a differentiated good always sets the optimal monopoly price, so

$$
P_{t}=\left(\frac{\varepsilon}{\varepsilon-1}\right) \frac{W_{t}}{A_{t}}
$$

Given the household's initial wealth; utility maximization requires choosing sequences of aggregate consumption, hours worked, and the values of all assets subject to

$$
P_{t} C_{t}+\frac{B_{t+1}}{1+i_{t}}+P_{t} \frac{S_{t+1}}{1-\delta} \leq W_{t} N_{t}+B_{t}+P_{t} S_{t}+D_{t}
$$

and the sequences of non-negativity constraints in (1) and (2). Here, $D_{t}$ is the dividend earned from the household's ownership of the differentiated-good producers, and $i_{t}$ is the interest rate given by $\rho(\cdot)$. If we denote the Lagrange multipliers on the year $t$ budget constraint and the non-negativity constraints on storage and labor with $\beta^{t} \lambda_{t} / P_{t}, \beta^{t} \lambda_{t} \nu_{t} /(1-\delta)$, and $\beta^{t} \lambda_{t} v_{t}$; the utility maximization problem yields familiar conditions for optimal labor supply, optimal bond purchases, and optimal storage.

$$
\begin{aligned}
\theta C_{t} & =\frac{W_{t}}{P_{t}}+v_{t} \\
1 & =\beta\left(1+i_{t}\right) \frac{P_{t} C_{t}}{P_{t+1} C_{t+1}} \\
1 & =\beta(1-\delta) \frac{C_{t}}{C_{t+1}}+\nu_{t}
\end{aligned}
$$


These, together with the transversality condition

$$
\lim _{t \rightarrow \infty} \beta^{t} \frac{S_{t+1}+B_{t+1} / P_{t+1}}{C_{t+1}}=0
$$

are necessary and sufficient for the household's utility maximization.

These results enable the definition of a flexible-price equilibrium. Given initial goods in storage $S_{0}$ and an interest rate rule $\rho(\cdot)$, this is a collection of sequences for $C_{t}, N_{t}, D_{t}, S_{t+1}, B_{t+1}, W_{t}, P_{t}$, and $i_{t}$ such that

- the sequences for $C_{t}, N_{t}, B_{t+1}$, and $S_{t+1}$ solve the household's utility maximization problem given $S_{0}$ and the sequences for $D_{t}, W_{t}, P_{t}$, and $i_{t}$;

- $P_{t}$ and $W_{t} / A_{t}$ satisfy (5);

- $B_{t+1}=0$ for all $t \geq 0$;

- the interest rate $i_{t}=\rho\left(\Omega_{t}\right)$, where $\Omega_{t}$ is as specified above; and

- labor markets clear

$$
A_{t} N_{t}=C_{t}+S_{t+1} /(1-\delta)-S_{t}
$$

There are many flexible-price equilibria, but they all share a single allocation of consumption, storage, and hours worked. Since I repeatedly reference this allocation's values below, I denote the associated values of $C_{t}, S_{t}$, and $N_{t}$ with $\tilde{C}_{t}, \tilde{S}_{t}$, and $\tilde{N}_{t}$. The tilde should bring flexibility to mind. To reduce the number of cases under review, I henceforth suppose that the economy starts with no consumption available from storage: $S_{0}=0$.

The flexible-price allocation's characterization depends on whether the real interest rate in the initial period,

$$
\tilde{R}_{0} \equiv \frac{\left(1+i_{0}\right) P_{0}}{P_{1}}=\frac{\beta^{-1} \tilde{C}_{1}}{\tilde{C}_{0}}
$$

strictly exceeds $1-\delta$ or instead equals this return to storage. In the former case, the storage technology is not used $\left(\tilde{S}_{t}=0\right.$ for all $\left.t \geq 1\right)$, and I call the associated expected famine mild. The latter case is that of a severe famine. 


\subsection{Mild Famines}

To begin this case's equilibrium analysis, suppose that indeed $\tilde{S}_{t}=0$ for all $t \geq 1$. The optimal price-setting condition in (5) determines $W_{t} / P_{t}$. Substituting this into the optimal labor-supply condition (7) yields

$$
\tilde{C}_{t}=\left(\frac{\varepsilon-1}{\varepsilon}\right) \frac{A_{t}}{\theta}
$$

This and the labor-market clearing condition together gives us

$$
\tilde{N}_{t}=\tilde{C}_{t} / A_{t}
$$

Setting $\tilde{S}_{t+1}=0$ is consistent with (9) for $t \geq 1$, because $\tilde{C}_{t}$ is constant from $t=1$ onwards and $\beta(1-\delta)<1$ from (3). From (10) and the household's Euler equation for nominal bonds, we know that $\tilde{R}_{0}=A^{L} /\left(\beta A^{H}\right)$. The precondition for a mild famine that $\tilde{R}_{0}>(1-\delta)$ therefore requires

$$
\frac{A^{L}}{\beta A^{H}}>1-\delta
$$

The inequality in (12) puts a lower bound on $A^{L}$ which defines a "mild" famine. When it holds good, $\tilde{S}_{t}=0$ and expressions for $\tilde{C}_{t}$ and $\tilde{N}_{t}$ in (10) and (11) together give the unique flexible-price equilibrium allocation.

Completing the construction of an equilibrium requires finding an interest rate rule for Joseph and sequences of nominal prices and wages that are consistent with this allocation. For the rule, consider

$$
i_{t}=\max \left\{0, \pi^{\star} \tilde{R}_{t}\left(\frac{\pi_{t}}{\pi^{\star}}\right)^{\phi}-1\right\},
$$

with $\tilde{R}_{t} \equiv \beta^{-1} \tilde{C}_{t+1} / \tilde{C}_{t}$. This is a censored inflation targeting rule with a timevarying intercept equal to the "natural" rate of interest. In it, $\pi^{\star}$ is the target inflation rate, $\pi_{0} \equiv P_{0} \pi^{\star}$, and $\pi_{t} \equiv P_{t} / P_{t-1}$ for $t \geq 1$. When $\pi_{t}=\pi^{\star}$, the underlying non-censored rule tracks the nominal interest rate consistent with the flexible-price allocation. Otherwise $\phi$ regulates the response of $i_{t}$ to deviations from the inflation target. If $\phi>1$, the rule satisfies the "Taylor principle." 
To construct an flexible-price equilibrium using (13), set $\pi^{\star} \geq \tilde{R}_{0}^{-1}$ and $P_{t}=\pi^{\star t}$. With these values, (13) gives $i_{t}=\pi^{\star} \tilde{R}_{t}-1$. This satisfies (8) for all $t \geq 0$; so this sequence of allocations, prices, and interest rates forms a flexible-price equilibrium.

In the constructed equilibrium, inflation is invariant to $\phi$. However, this invariance occurs only because $R_{0} \pi^{\star} \geq 1$, which in turn guarantees that the equilibrium avoids the zero lower bound. If instead $R_{0} \pi^{\star}<1$ (which is the case of greatest interest when there are nominal rigidities), then (13) sets $i_{0}$ to zero if $\pi_{0}=\pi^{\star}$. With this interest rate, clearing the nominal bond market (given $C_{t}=\tilde{C}_{t}$ always) requires $\pi_{1}$ to exceed $\pi^{\star}$. For reasons familiar from Benhabib, Schmitt-Grohé, and Uribe (2001), the evolution of subsequent inflation depends on $\phi$. If $\phi<1$, then inflation temporarily overshoots $\pi^{\star}$. If instead $\phi=1$, then inflation remains permanently at $\pi_{1}$. Finally, with $\phi>1$ the Taylor principle induces Joseph to raise the nominal interest rate more than one-for-one with inflation. Bond-market clearing then requires inflation to rise even further, leading to an explosive inflation sequence. Regardless of its implications for inflation, the interest rate rule has no influence on flexible price allocations.

\subsection{Severe Famines}

Now, suppose $\tilde{R}_{0}=(1-\delta)$ and $\nu_{0}=0$, which allows $\tilde{S}_{1}>0 .{ }^{3}$ As in the case of a mild famine, $v_{0}=0$ and Equation (10) determine $\tilde{C}_{0}$. To determine $\tilde{C}_{t}$ for $t \geq 1$, use the Euler equation for optimal storage to get

$$
\tilde{C}_{1}=\beta(1-\delta) \tilde{C}_{0}
$$

Since the economy faces a severe famine, this exceeds the value of $C_{1}$ consistent with setting $N_{1}>0$. Therefore, $\tilde{N}_{1}=0$.

The upper bound on $1-\delta$ embodied in (3) ensures that the rate of return from saving from year 1 to year 2 is small enough to be consistent with the household setting $S_{2}$ to zero. Although none of the results below depend on this particular limit on the duration of storage, it does simplify the analysis considerably. With this, $\tilde{S}_{t}=0$ and (10) characterizes $\tilde{C}_{t}$ for all $t \geq 2$.

Given the sequences for $\tilde{C}_{t}$ and $\tilde{S}_{t}$ in hand, the labor-market clearing conditions determine $\tilde{N}_{t}$ for $t=0$ and $t \geq 2$. The consumption sequence and (8) determine

\footnotetext{
${ }^{3}$ This requires $\beta A^{H} / A^{L} \geq 1 /(1-\delta)$.
} 
equilibrium real interest rates. To decompose these into nominal interest rates and inflation; use the interest rate rule in (13). Just as with a mild famine, $i_{0}>0$ and $\pi_{t}=\pi^{\star}$ for all $t$ if $\tilde{R}_{0} \pi^{\star}>1$. Otherwise, $i_{0}=0$ and $\pi_{t}>\pi^{\star}$ always.

Figure 1 summarizes this section's results with (qualitative) plots of the flexibleprice allocation and its associated real interest rate over time. In each panel, the blue line with circles corresponds to the case of a mild famine, while the orange line with squares gives analogous values for a severe famine. The upper-right panel plots productivity for the two cases, which share a common value for $A^{H}$. The upper-left panel gives consumption, which begins at $\tilde{C}_{0}$ in both cases. With the mild famine, it falls to $\tilde{C}_{1}$ and stays there forever. With a severe famine, the household carries wealth into year 1 , so in this case $\tilde{C}_{1}>\tilde{C}_{2}$. Regardless, consumption reaches its long-run value in year 2.

The lower-left panel gives the associated gross real interest rates, $\tilde{R}_{t}$, which do not depend on the particular nominal interest rate rule employed by Joseph. With a mild famine, $\tilde{R}_{0}=A^{L} /\left(\beta A^{H}\right)$. Making the foreseen famine worse by lowering $A^{L}$ reduces this until it reaches $1-\delta$. For even smaller values of $A^{L}$, the household's use of the storage technology keeps this "natural" interest rate from falling. With a mild famine, the real interest rate reaches its long-run value, $1 / \beta$, in year 1 . In the case of a severe famine, the real interest rate remains below $1 / \beta$ in year 1 because consumption is still higher than its long-run value.

Finally, the lower-right panel gives hours worked in the two cases. Under a mild famine, the ratio of consumption to wages is constant. Since these preferences satisfy standard balanced-growth restrictions, this means that wage changes' income and substitution effects exactly offset to leave hours worked constant. The case of a severe famine shows the Lucas and Rapping (1969) theory of intertemporal substitution and labor supply in action. Temporarily high real wages in year 0 induce the household to expand labor supply, accumulate savings, and raise consumption in future years. The future consumption boom lowers hours worked for the one year that it lasts.

\section{Equilibria with Nominal Rigidities}

This section shows how nominal rigidities can interfere with implementing the non trivial intertemporal substitution of the flexible-price allocation. This requires re- 
Figure 1: The Flexible-Price Allocation and Real Interest Rate
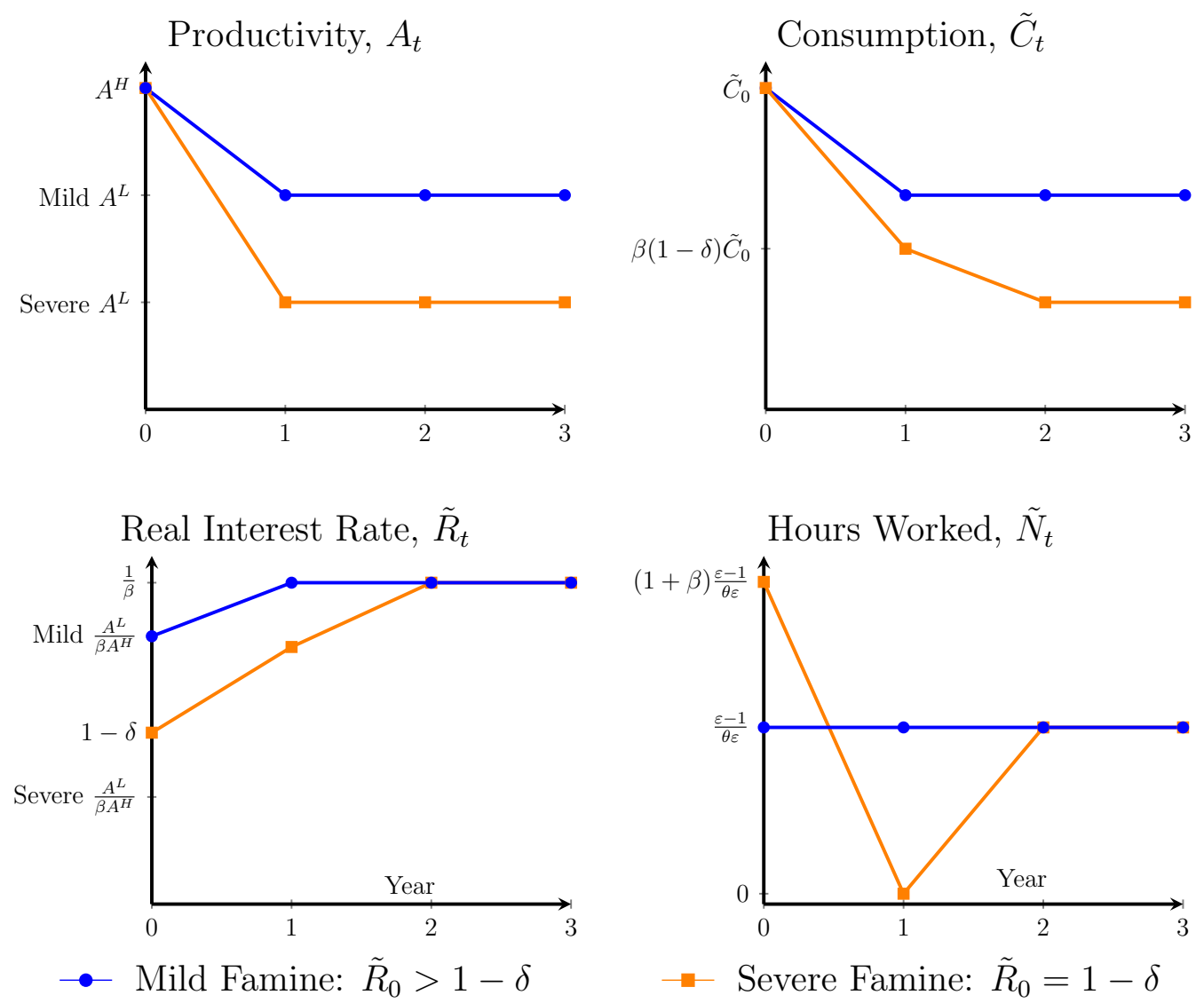

- Mild Famine: $\tilde{R}_{0}>1-\delta$

- Severe Famine: $\tilde{R}_{0}=1-\delta$ 
examining producers' optimal pricing decisions and appropriately redefining equilibrium. For this section, I continue to hold $B_{t+1}=Q_{t+1}=0$, so the resulting equilibria are without $J Q E$.

Denote the price chosen by a firm in year $t-j$ that will apply in year $t$ with $P_{t}^{j}$; so $P_{t}^{0}$ is the price chosen by producers with a current price choice, and $P_{t}^{1}$ is the price for $t$ chosen by producers that set their year $t$ price in $t-1$.

Since there is no uncertainty, the optimal price choices are

$$
\begin{aligned}
P_{t}^{0} & =\left(\frac{\varepsilon}{\varepsilon-1}\right) \frac{W_{t}}{A_{t}} \forall t \geq 0 \text { and } \\
P_{t}^{1} & =\left(\frac{\varepsilon}{\varepsilon-1}\right) \frac{W_{t}}{A_{t}} \forall t \geq 1 .
\end{aligned}
$$

The right-hand sides of (15) and (16) are identical, but they apply to different years. The preset price, $P_{0}^{1}$, is one of the economy's initial conditions; which I normalize to one. With these firm-level prices, the aggregate price index is

$$
P_{t}=\left(\frac{1}{2} P_{t}^{01-\varepsilon}+\frac{1}{2} P_{t}^{11-\varepsilon}\right)^{\frac{1}{1-\varepsilon}} .
$$

The definition of an equilibrium with nominal rigidities uses these conditions instead of the optimal flexible pricing rule in (5). Given the preset price $P_{0}^{1}=1$, the initial stock goods in storage $S_{0}$, and an interest rate rule $\rho(\cdot)$, an equilibrium with nominal rigidities is a collection of sequences for $C_{t}, N_{t}, D_{t}, S_{t+1}, B_{t+1}, W_{t}$, $P_{t}^{0}, P_{t}^{1}, P_{t}$, and $i_{t}$ such that

- the sequences for $C_{t}, N_{t}, B_{t+1}$, and $S_{t+1}$ solve the household's utility maximization problem given $S_{0}$ and the sequences for $D_{t}, W_{t}, P_{t}$, and $i_{t}$;

- $P_{t}^{0}$ and $W_{t} / A_{t}$ satisfy (15) for all $t \geq 0$;

- $P_{t}^{1}$ and $W_{t} / A_{t}$ satisfy (16) for all $t \geq 1$;

- $P_{t}^{0}, P_{t}^{1}$, and $P_{t}$ satisfy (17) for all $t \geq 0$;

- $B_{t+1}=0$ for all $t \geq 0$;

- the interest rate rule in (13) determines $i_{t}$; and 
- labor markets clear

$$
\frac{A_{t} N_{t}}{\frac{1}{2}\left(\frac{P_{t}^{0}}{P_{t}}\right)^{-\varepsilon}+\frac{1}{2}\left(\frac{P_{t}^{1}}{P_{t}}\right)^{-\varepsilon}}=C_{t}+S_{t+1} /(1-\delta)-S_{t} .
$$

Here, total output is written as a linear function of hours worked, with "productivity" dependent on differentiated goods' producers' relative prices. This is at its maximum when all goods' nominal prices equal each other. ${ }^{4}$ This definition also imposes the particular interest rate rule (13) on Joseph, since it is the only specification for $\rho\left(\Omega_{t}\right)$ examined henceforth.

Because there is no extrinsic uncertainty and I focus on non stochastic equilibria, the optimal pricing conditions in (15) and (16) imply that the only possible nominal distortion in equilibrium occurs in the initial year. This alone implies that every equilibrium sequence corresponds to some flexible price equilibrium from year 1 onwards. ${ }^{5}$ Therefore, Joseph cannot escape a liquidity trap by making a (timeinconsistent) promise to stimulate the economy in the future so that $C_{1}>\tilde{C}_{1}$. This limitation on nominal rigidities combined with the bound on storage technology's return in (3) focuses the analysis on intertemporal substitution between years 0 and 1 and the nominal obstacles to its efficient execution. However, accounting for an infinite horizon instead of collapsing the analysis to two periods brings one important advantage. Because a conventional Taylor rule determines the nominal interest rate, the role of well-anchored and rational long-run inflation expectations to select from the equilibrium set can be examined coherently.

\subsection{The Phillips Curve}

Generically, this economy has multiple equilibrium allocations. When $\pi_{1}$ indexes the equilibrium set, Joseph can guide the economy to a desired outcome by appropriately managing inflation expectations. (The tools of an inflation-targeting regime (Bernanke and Mishkin, 1997) could be useful for this task.) In other cases, $\pi_{1}$ is constant across equilibria and instead they differ in the expected (and realized) value of $C_{1}$. (This paper shows how JQE can manage these expectations of future

\footnotetext{
${ }^{4}$ To show this, use (17), the fact that $x^{\frac{\varepsilon}{\varepsilon-1}}$ is convex if $\varepsilon>0$, and Jensen's inequality.

${ }^{5}$ The characterization of these flexible-price equilibria might require extending the analysis of Section 3 by accounting for initial wealth in storage.
} 
consumption.) Both cases can be understood as specific instances of a fundamental multiplicity that arises in the model when the only dynamic considerations come from firms' preset prices. That is, the economy has neither a bond market nor a storage technology. The set of equilibrium allocations in this relatively static economy traces out the economy's Phillips curve.

In year 0 , half of the firms have nominal prices fixed at $P_{0}^{1}=1$, while the other half can choose their nominal prices. Additionally, the household provides labor and spends all of its income on consumption. Given $P_{0}^{1}=1$, equilibrium in this alternative economy requires $C_{0}, N_{0}, W_{0}, P_{0}$, and $P_{0}^{0}$ to satisfy the optimal labor supply condition in $(7)$ with $v_{0}$ set to zero, the optimal pricing condition in (15), the price aggregation rule in (17), and the labor market clearing condition in (18) with $S_{0}$ and $S_{1}$ set to zero.

Four conditions restrict five unknowns. To show mechanically that this under determination indeed results in equilibrium multiplicity, define $\varsigma \equiv(1 / 2)^{1 /(\varepsilon-1)} \in$ $(0,1)$ and select any

$$
C_{0}>\varsigma \tilde{C}_{0}
$$

Intuitively, imposing sticky prices on some of the economy's goods cannot reduce consumption more than would eliminating those goods from production altogether. The lower bound for $C_{0}$ in (19) imposes this intuition, which turns out to be essential for characterizing the Phillips curve. With $C_{0}$ in hand, the optimal labor supply condition determines the real wage $W_{0} / P_{0}$. Combining this with the conditions for optimal flexible prices and price aggregation and manipulating the result yields

$$
P_{0}=\left(\frac{\frac{1}{2}}{1-\frac{1}{2}\left(\frac{C_{0}}{\tilde{C}_{0}}\right)^{1-\varepsilon}}\right)^{\frac{1}{1-\varepsilon}}
$$

This positively connects the consumption gap, $C_{0} / \tilde{C}_{0}$, with inflation, $\pi_{0} / \pi^{\star} \equiv P_{0}$. The assumed lower bound for $C_{0}$ in (19) guarantees that the expression for $P_{0}$ is real. Because firms' choices of current prices do not constrain their choices of future prices, this Phillips curve does not have the dependence on expected future inflation familiar from the standard New Keynesian Phillips curve derived from the Calvo (1983) pricing technology. ${ }^{6}$

\footnotetext{
${ }^{6}$ For simplicity only, equal fractions of firms have sticky and flexible prices in year 0. If instead
} 
Figure 2: The Phillips Curve

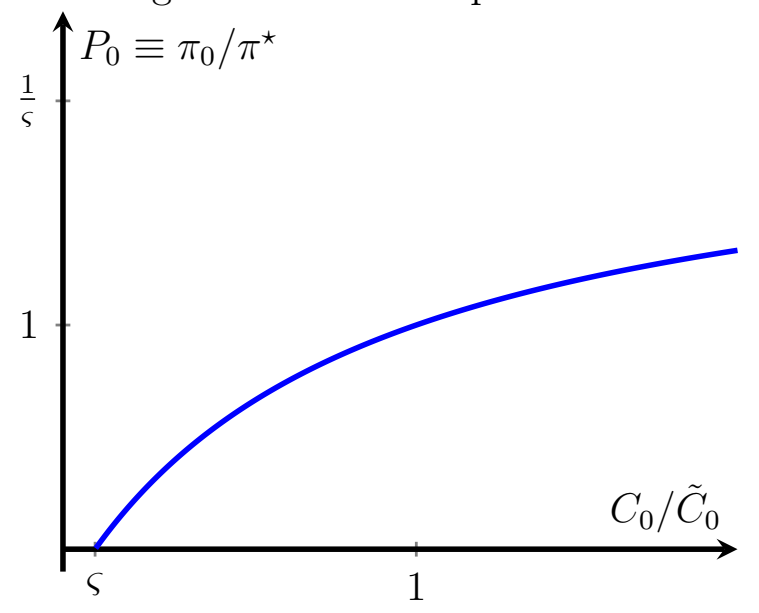

Figure 2 presents this Phillips curve graphically, with $C_{0} / \tilde{C}_{0}$ on the horizontal axis. It begins arbitrarily close to the point $(\varsigma, 0)$, crosses through the $45^{\circ}$ line at $(1,1)$, and asymptotes to $1 / \varsigma$ as $C_{0} / \tilde{C}_{0}$ goes to infinity. Any point on this Phillips curve is consistent with equilibrium: Given $C_{0}$ and $P_{0}$ from such a point, $W_{0}$ and $P_{0}^{0}$ can be obtained immediately from (7) and (15). The labor market clearing condition then determines $N_{0}$.

Economically, the Phillips curve reflects a coordination failure (Cooper and John, 1988). Producers with flexible prices must coordinate on an expectation of real marginal cost, $W_{0} /\left(A_{0} P_{0}\right)$. Increasing this expectation raises their prices and lowers the economy's average markup over marginal cost, thereby boosting economic activity. This raises marginal cost through (7), so firms' expectations of higher marginal cost are fulfilled. ${ }^{7}$

a fraction $\lambda$ of firms had flexible prices, then the expression for the Phillips curve in (20) would be

$$
P_{0}=\left(\frac{1-\lambda}{1-\lambda\left(\frac{C_{0}}{\tilde{C}_{0}}\right)^{1-\varepsilon}}\right)^{\frac{1}{1-\varepsilon}}
$$

Furthermore, the definition for $\varsigma$ in (19) would become $\varsigma \equiv \lambda^{\frac{1}{\varepsilon-1}}$. Intuitively, $\varsigma$ converges to one as $\lambda \rightarrow 1$ and price rigidity vanishes.

${ }^{7} \mathrm{~A}$ host of macroeconomic models feature equilibrium multiplicity. Among those, the one most closely related to this fundamental multiplicity is that of Shleifer (1986). That model also omits external effects of production and derives equilibrium multiplicity from a static coordination failure. However, its coordination failure concerns technological development, which is arguably more relevant for medium-run fluctuations than are this model's short-run pricing decisions. 
Equilibrium multiplicity in the full model can be better understood in light of the Phillips curve by considering the Euler equation for optimal nominal bond purchases, (8). Given $i_{0}, \pi_{1}$, and $C_{1}$, this determines $C_{0}$ and thereby selects one of many points on the Phillips curve of Figure 2. In the "standard" analysis of liquidity traps with discretionary monetary policy, $i_{0}=0$ and $C_{1}$ is assumed to equal $\tilde{C}_{1}$. Then, inflation expectations determine current macroeconomic performance, as in Krugman (1998). For the present model, Subsection 4.3 covers this case in detail

by assuming that the famine is mild. With storage, $C_{1}$ becomes endogenous; even if we assume that it equals its flexible-price value given $S_{1}$. In this case - which is covered in Subsection 4.4 given a severe famine - the economy can have multiple equilibria with constant (across equilibria) values of $i_{0}$ and $\pi_{1}$.

\subsection{The Flexible-Price Allocation Replicator}

An equilibrium with nominal rigidities can exhibit the familiar Keynesian connection between disinflation and output in the initial year, because adjustments of $P_{0}^{0}$ influence consumption and marginal cost and thereby change the average markup of producers with fixed nominal prices. However, as Cochrane (2013) noted, this is not a necessary feature of equilibrium in a new Keynesian economy. When Joseph follows an interest rate rule like (13), then there always exists an equilibrium that implements the flexible-price allocation. As in the examples considered by Cochrane in the standard three-equation model, this requires inflation to overshoot $\pi^{\star}$ when $\tilde{R}_{0} \pi^{\star}<1$.

I call this equilibrium the flexible-price allocation replicator. Begin its construction by assigning the interest rate rule in (13) to Joseph with a specific value of $\pi^{\star}$; and setting $C_{t}, N_{t}$, and $S_{t+1}$ to $\tilde{C}_{t+1}, \tilde{N}_{t+1}$, and $\tilde{S}_{t+1}$ respectively. Select $P_{0}^{0}=1$ and $\pi_{1}$ to satisfy (8) given $i_{0}, C_{0}$, and $C_{1}$. If $\tilde{R}_{0} \pi^{\star} \geq 1$, then $\pi_{1} \leq \pi^{\star}$. Otherwise, $\pi_{1}>\pi^{\star}$. In either case, evaluate both the Euler equation for bonds (8) and the interest rate rule in (13) at the flexible price allocation and combine them to get a forward-looking first-order difference equation for inflation

$$
\pi_{t+1}=\beta \max \left\{1, \pi^{\star} \beta^{-1}\left(\frac{\pi_{t}}{\pi^{\star}}\right)^{\phi}\right\}
$$

for all $t \geq 1$. Given $\pi_{1}$, this determines $\pi_{t}$ for all $t \geq 2$. Feeding $\pi_{t}$ into (13) then 
yields $i_{t}$ for $t \geq 1$. The long-run behavior of inflation depends on $\phi$ and $\tilde{R}_{0} \pi^{\star}$ exactly as discussed at the end on Section 3.1. In particular, if $\tilde{R}_{0} \pi^{\star}<1$ and $\phi>1$, then implementing the flexible-price allocation requires an explosive inflation sequence. To the extent that central banks facing actual liquidity traps have set inflation targets that are both credible and inappropriately low, the flexible-price allocation replicator delineates the problem of escaping a liquidity trap rather than solving it.

\subsection{Mild Famines}

Although liquidity traps driven by low inflation expectations and a mild anticipated famine are not this paper's focus, they exemplify the now-standard analysis of monetary policy at the zero lower bound. To construct a liquidity trap equilibrium that resembles the "discretionary" equilibrium of Eggertsson and Woodford (2003), presume that consumption, storage, and hours worked equal $\tilde{C}_{t}, \tilde{S}_{t}$, and $\tilde{N}_{t}$ for $t \geq 1$. Next select a value for $\pi^{\star}$ and another for

$$
\pi_{1} \in\left(\varsigma / \tilde{R}_{0}, \max \left\{1 / \tilde{R}_{0}, \pi^{\star}\right\}\right]
$$

Given these choices, any equilibrium value for $C_{0}$ must satisfy

$$
C_{0}=\frac{\pi_{1} \tilde{C}_{1}}{\beta \max \left\{1, \pi^{\star} \tilde{R}_{0} P_{0}\left(C_{0}\right)^{\phi}\right\}} .
$$

It is straightforward to use the restrictions on $\pi_{1}$ in (22) to show that there exists a unique $C_{0} \in\left({ }_{\varsigma} \tilde{C}_{0}, \tilde{C}_{0}\right]$ that satisfies (23). Since $C_{0} \leq \tilde{C}_{0}$ and the famine is mild,

$$
\nu_{0} \equiv 1-\beta(1-\delta) \frac{C_{0}}{C_{1}}=1-\beta(1-\delta) \frac{C_{0}}{\tilde{C}_{1}} \geq 1-\beta(1-\delta) \frac{\tilde{C}_{0}}{\tilde{C}_{1}}=1-(1-\delta) / \tilde{R}_{0}>0
$$

Therefore, $S_{0}=0$. Applying the Phillips curve then yields $P_{0}$; and $W_{0}$ and $P_{0}^{0}$ both follow immediately from the necessary conditions for household's optimal labor supply and firms optimal price choices. The labor-market clearing condition in (18) then yields $N_{0}$. Finally, use the difference equation for inflation in (21) to determine $\pi_{t}$ for $t \geq 2$ and then apply the interest rate rule in (13) to get $i_{t}$ for $t \geq 1$. I summarize this equilibrium construction with a 
Proposition 1. Suppose that $\tilde{R}_{0}>(1-\delta)$ and select $\pi_{1}$ that satisfies (22). Then there exists a equilibrium with nominal rigidities in which $\pi_{t}$ equals the given value of $\pi_{1}$ for $t=1, S_{t+1}=0$ for all $t \geq 0, C_{0}<\tilde{C}_{0}$ and $C_{t}=\tilde{C}_{t}$ for all $t \geq 1$.

In the equilibria of Proposition 1, short-run inflation expectations that are too low cause a real recession. Whether or not $i_{0}=0$ as in other models' liquidity traps depends on $\pi^{\star}$ and $\phi$. If $\tilde{R}_{0} \pi^{\star} \leq 1$, then $i_{0}$ must equal zero. If instead $\tilde{R}_{0} \pi^{\star}>1$, then the initial deflation forces $i_{0}$ to hit the zero lower bound when $\phi$ is large enough. These equilibria can be unambiguously labelled liquidity traps. However, $i_{0}$ can exceed zero if both $\tilde{R}_{0} \pi^{\star}>1$ and $\phi$ is small. ${ }^{8}$

With the caveat that $i_{0}$ might be positive, I will hereafter refer to the equilibria of Proposition 1 as liquidity traps. Clearly, their multiplicity (indexed by $\pi_{1}$ ) arises from the fundamental multiplicity that underlies the Phillips curve. Their traditional interpretation labels $C_{0}$ aggregate demand. In this story, monetary policy that is made too tight by the zero lower bound and inappropriately low inflation expectations lowers aggregate demand through the Euler equation for bonds (8), and this brings about an accompanying deflation. Indeed, the equilibrium construction does lead from the determination of $C_{0}$ in the bond market to the value of $P_{0}$ required to support that outcome. In this sense, the equilibrium of Proposition 1 conforms to the familiar pattern of other new Keynesian models of liquidity traps.

Implicitly, Proposition 1 embodies the now conventional policy prescription for avoiding a liquidity trap: either have the good fortune to have a credible inflation target which exceeds the natural rate of interest's inverse after the shock to desired savings $\left(\pi_{1}=\pi^{\star}>\tilde{R}_{0}^{-1}\right)$ or somehow convince the public that $\pi_{1}=\tilde{R}_{0}^{-1}$ even though this requires missing the stated inflation target. In either case, Joseph could set nominal bonds' real return to the value required by the flexible price allocation with a non negative nominal interest rate.

If we set $\phi>1$ and presume that $\pi_{t}=\pi^{\star}$ in the long run (for large $t$ ), then the inflation target's assumed long-run credibility and the Taylor principle mathematically guarantee that $\pi_{1}=\pi^{\star}$. In light of Cochrane's (2011) extensive critique of this scheme's economic foundations (or lack thereof), I choose not to adopt it as a useful resolution of equilibrium indeterminacy. Nevertheless, it is worth understanding how such an "active" monetary policy selects from the equilibrium set if only

\footnotetext{
${ }^{8}$ In this somewhat perverse case, $\pi_{1}<\pi^{\star}$ and $i_{0}>0$. A lower but still positive policy rate could set bonds' real return to $\tilde{R}_{0}$ (given $\pi_{1}$ ).
} 
because it is commonly embodied in applied work. If $\tilde{R}_{0} \pi^{\star}<1$, then this selected equilibrium is one of the liquidity traps from Proposition (1). If instead $\tilde{R}_{0} \pi^{\star} \geq 1$, then this equilibrium replicates the flexible-price allocation. ${ }^{9}$

\subsection{Severe Famines}

Storage occurs in the flexible-price allocation when the expected famine is severe, but inappropriately low inflation expectations can eliminate all equilibria in which storage occurs. Intuitively, if expected inflation is low enough, the real return on bonds must exceed that of storage.

Proposition 2. There exists no equilibrium with nominal rigidities in which both $S_{1}>0$ and $\pi_{1}<1 /(1-\delta)$.

Proof. Suppose otherwise. Since $S_{1}>0$, we can rearrange (8) and (9) to get

$$
\frac{1+i_{0}}{\pi_{1}}=(1-\delta)
$$

Therefore

$$
1+i_{0}=\pi_{1}(1-\delta)<1
$$

This violates the zero-lower bound on interest rates.

\subsubsection{Liquidity Traps}

Proposition 2 only says that storage cannot occur with low inflation expectations. The following proposition shows that liquidity trap equilibria (like those characterized above for a mild famine) exist even in a severe famine.

Proposition 3. Suppose that $\tilde{R}_{0}=1-\delta$ and select

$$
\pi_{1} \in\left(\varsigma \beta \frac{A^{H}}{A^{L}}, \frac{1}{1-\delta}\right] .
$$

Then there exists an equilibrium with nominal rigidities with the consumption, hours worked, and storage sequences from the equilibrium of Proposition 1 with the same value of $\pi_{1}$ given any alternative value for $\delta$ that satisfies $1-\delta<\tilde{R}_{0}$.

\footnotetext{
${ }^{9}$ For the sake of completeness; note that if $\tilde{R}_{0} \pi^{\star} \leq \varsigma$ and $\phi>1$, then there is no equilibrium with $\lim _{t \rightarrow \infty} \pi_{t}=\pi^{\star}$.
} 
Proof. Begin by setting $C_{t}=\tilde{C}_{t}, S_{t}=\tilde{S}_{t}$, and $N_{t}=\tilde{N}_{t}$ for $t \geq 2$, and define

$$
C^{\star} \equiv\left(\frac{\varepsilon-1}{\varepsilon}\right) \frac{A^{L}}{\theta}
$$

This is the only value for $C_{1}$ consistent with non negativity of $N_{1}$ if $S_{1}=0$. Given $C_{1}=C^{\star}$, the Euler equation for bonds (8) and the interest rate rule (13) together require

$$
C_{0}=\frac{\pi_{1} C^{\star}}{\beta \max \left\{1, \pi^{\star} \tilde{R}_{0} P_{0}\left(C_{0}\right)^{\phi}\right\}} .
$$

Verifying that there exists a unique real value of $C_{0}$ that satisfies (24) for every value of $\pi_{1}$ in the admissible interval is straightforward. Use this solution for $C_{0}$; and set $P_{0}, W_{0}, P_{0}^{0}$, and $N_{0}$ as in the construction preceding Proposition 1 . That construction used the presupposition that the famine was mild to verify that the implied value of $\nu_{0} \geq 0$. To do the same here, use the Euler equation for the optimal purchase of bonds and the upper bound on $\pi_{1}$ to get.

$$
\frac{\beta C_{0}}{C_{1}}(1-\delta)=\frac{\pi_{1}(1-\delta)}{1+i_{0}}<\frac{1}{1+i_{0}} \leq 1
$$

So again, $\nu_{0}=1-(1-\delta) \beta C_{0} / C_{1}>0$.

Before continuing, it is worth establishing that all of the equilibria characterized by Proposition 3 are recessionary, in the sense that real GDP is less than its potential value, $C_{0}+S_{1}<\tilde{C}_{0}+\tilde{S}_{1}$. To see this, note from (24) that $C_{0}$ increases with $\pi_{1}$. Using the stated upper bound for $\pi_{1}$ therefore yields

$$
C_{0} \leq \beta^{-1}(1-\delta)^{-1} C^{\star} \leq \beta^{-1}(1-\delta)^{-1} \tilde{C}_{1}=\tilde{C}_{0}
$$

By construction, $S_{1}=0 \leq \tilde{S}_{1}$, so indeed the total output gap is negative. As in the case with a mild famine, whether or not these recessionary equilibria also feature $i_{0}=0$ depends on the inflation target. If $\pi^{\star}(1-\delta) \leq 1$, then all of these equilibria have $i_{0}=0$. If instead $\pi^{\star}(1-\delta)>1$, then the equilibrium's initial deflation might or might not force $i_{0}$ to hit its zero lower bound.

Proposition 3 illustrates two aspects of liquidity traps in an economy with storage. First, the storage technology is irrelevant to households given that the economy is in a liquidity trap. Intuitively, bonds' rate of return dominates that of storage in 
such equilibria. Second, this does not imply that storage is irrelevant for escaping a liquidity trap. To see this, consider the best equilibrium of Proposition 3. In it, the real interest rate on bonds equals the return to storage, which is also the "natural" rate of interest. Nevertheless, that equilibrium's output gap is strictly negative. This is one example of a confidence recession, in which $C_{0}<\tilde{C}_{0}, N_{0}<\tilde{N}_{0}$, and $S_{1}<\tilde{S}_{1}$ even though $\left(1+i_{0}\right) / \pi_{1}=(1-\delta)$.

\subsubsection{Confidence Recessions}

To characterize all such confidence recessions, select

$$
C_{1} \in\left[C^{\star}, \tilde{C}_{1}\right)
$$

Given $C_{1}$, set $C_{0}=\beta^{-1}(1-\delta)^{-1} C_{1}$. With this value of $C_{0}$, the nominal interest rate equals

$$
i_{0}=\max \left\{0, \pi^{\star}(1-\delta) P_{0}\left(\beta^{-1}(1-\delta)^{-1} C_{1}\right)^{\phi}-1\right\} .
$$

Setting

$$
\pi_{1}=\frac{1+i_{0}}{1-\delta}
$$

ensures that the real interest rate equals $1-\delta$, so (8) is satisfied. ${ }^{10}$ Determining values for $W_{0}, P_{0}^{0}$, and $P_{0}$ consistent with the optimal labor supply, optimal price setting, and price aggregation conditions in (7), (15), and (17) is then straightforward. The optimal labor supply condition requires that $N_{1}=0$ whenever $C_{1}$ exceeds its lower bound in (25), so the resulting requirement that year 0 production equals $C_{0}+S_{1}=C_{0}+C_{1} /(1-\delta)$ determines $N_{0} \cdot{ }^{11}$ The upper bound on the return from storage in (3) allows us to set the remaining values of $C_{t}, S_{t}$, and $N_{t}$ to $\tilde{C}_{t}, \tilde{S}_{t}$, and $\tilde{N}_{t}$ respectively. The equilibrium construction continues by recursively using the inflation-evolution equation in (21) to determine $\pi_{t}$ for $t \geq 2$. With the inflation sequence in hand, the interest rate rule in (13) gives $i_{t}$ for $t \geq 1$. Again, I summarize this equilibrium with a

Proposition 4. Select $C_{1}$ from the interval in (25). Then there exists an equilibrium with nominal rigidities with the given value of $C_{1}$ and $C_{0} \leq \tilde{C}_{0}$. In this equilibrium,

\footnotetext{
${ }^{10}$ Since $C_{1} \geq C^{\star}$, we know that $C_{0} \geq \beta^{-1}(1-\delta)^{-1} C^{\star}$, the largest value of $C_{0}$ in an equilibrium of Proposition 2.

${ }^{11}$ If instead the imposed lower bound on $N_{1}$ was positive, then $N_{0}$ would be reduced accordingly.
} 
Figure 3: The Intertemporal-Substitution (IS) Curve

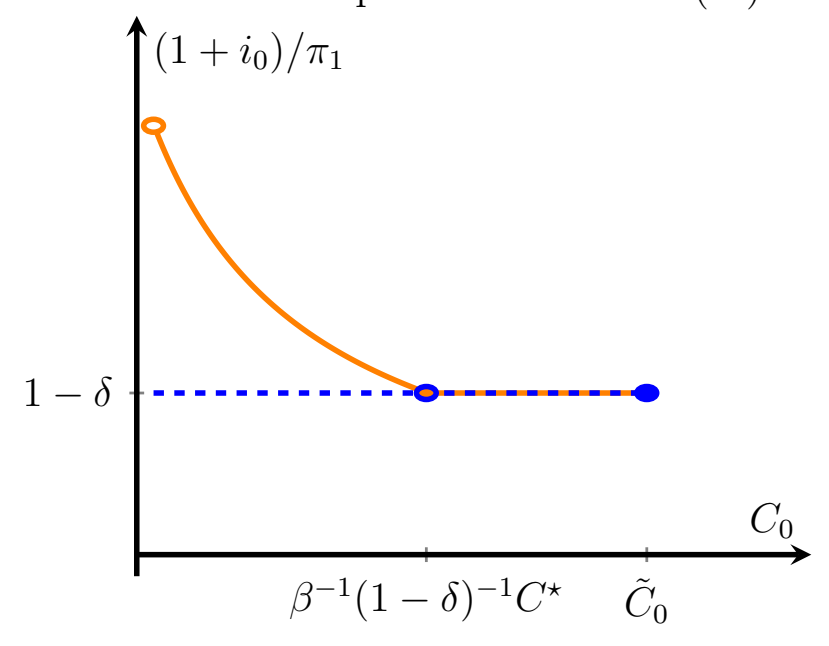

$\left(1+i_{0}\right) / \pi_{1}=(1-\delta)$; and $i_{0}=0$ if $\pi^{\star}(1-\delta)<1$. Furthermore, $C_{0}$ and $N_{0}$ are strictly increasing with the chosen value for $C_{1}$.

In these confidence recessions, households' choices of storage are strategic complements, and this complementarity arises from the fundamental multiplicity combined with the endogeneity of $C_{1} \cdot{ }^{12}$ Furthermore, confidence recessions might appear to be a symptom of the zero lower bound if $\pi^{\star}(1-\delta)<1$, because in this case $i_{0}=0$. However, bonds' rate of return equals the "natural" rate of interest in all confidence recessions. Indeed, reducing real interest rates with further monetary accommodation is not possible.

\subsubsection{The IS Curve}

Figure 3 summarizes these results with an intertemporal-substitution (IS) curve, which gives the combinations of real interest rates and consumption consistent with the equilibria of Propositions 3 and 4. An empty orange circle denotes the limit as $C_{0}$ is driven to its lower bound in (19), while a solid blue circle marks the equilibrium

\footnotetext{
${ }^{12}$ One might hypothesize that the equilibrium multiplicity demonstrated by Proposition 4 arises from the anticipation of different paths for inflation and nominal interest rates. To show that this is incorrect, set $\phi$ to zero. In this special case of extremely passive interest-rate policy, the equilibria of Proposition 4 share common inflation and interest-rate sequences: $\pi_{t}=\pi^{\star}$ and $i_{t}$ always equals the "natural" interest rate in the intercept of (13).
} 
that implements the flexible-price allocation. ${ }^{13}$ If bonds' real return exceeds $1-\delta$, then $S_{1}=0$. Over this range, the IS curve inherits its shape from the Euler equation (8). These equilibria are the model's liquidity traps from Proposition 3. Joseph could choose any of these equilibria if he had complete control over $\pi_{1}$.

If instead bonds' real return equals $(1-\delta)$, Proposition 4 tells us that any

$$
C_{0} \in\left[\beta^{-1}(1-\delta)^{-1} C^{\star}, \tilde{C}_{0}\right)
$$

is consistent with equilibrium. Therefore, the IS curve becomes horizontal. All points on this horizontal segment to the left of the blue dot represent confidence recessions. In all but one of these, the transitional equilibrium point denoted by a blue circle filled with orange where the IS curve's horizontal segment begins, $S_{1}>0$. The transitional equilibrium is both a liquidity trap and a confidence recession. In it, the non-negativity constraint on storage does not bind. Nevertheless, the household chooses $S_{1}=0 .{ }^{14}$

The IS curve's horizontal segment suggests that Joseph might not be able to avoid a confidence recession even if monetary policy could somehow determine $\left(1+i_{0}\right) / \pi_{1}$. On the other hand, if both $\pi^{\star}>1 /(1-\delta)$ and $\phi>0$, then the confidencerecession equilibria all have $\lim _{t \rightarrow \infty} \pi_{t}=\beta$. In this case, the only equilibrium with $\lim _{t \rightarrow \infty} \pi_{t}=\pi^{\star}$ implements the flexible-price allocation, so well-anchored long-run inflation expectations are sufficient for avoiding confidence recessions. The next section shows that properly-implemented JQE can accomplish the same goal given any interest rate rule without any auxiliary assumption on long-run inflation expectations.

\section{$5 \quad$ Josephean Quantitative Easing}

Incorporating JQE into the analysis requires giving control over $B_{1}$ and $Q_{1}$ to Joseph (subject to the feasibility constraint in (4)) and modifying the definition of an equilibrium with nominal rigidities accordingly. Given the preset price $P_{0}^{0}=1$, and no prior storage $S_{0}=Q_{0}=B_{0}=0$; then such an equilibrium with nominal rigidities

\footnotetext{
${ }^{13}$ Because Proposition 4's interval for $C_{1}$ is open to the right, it does not include this flexible-price equilibrium. However, this equilibrium is indeed the limit as $C_{1} \rightarrow \tilde{C}_{1}$.

${ }^{14}$ In the more general case with a strictly increasing marginal cost of storage examined in the appendix, the analogous IS curve features confidence recessions but has no horizontal segment.
} 
and JQE consists of sequences for $C_{t}, N_{t}, D_{t}, S_{t+1}, B_{t+1}, Q_{t+1}, W_{t}, P_{t}^{0}, P_{t}^{1}, P_{t}$, and $i_{t}$ such that

- the sequences for $C_{t}, N_{t}, B_{t+1}$, and $S_{t+1}$ solve the household's utility maximization problem given $S_{0}$ and the sequences for $D_{t}, W_{t}, P_{t}$, and $i_{t}$;

- $P_{t}^{0}$ and $W_{t} / A_{t}$ satisfy (15) for all $t \geq 0$;

- $P_{t}^{1}$ and $W_{t} / A_{t}$ satisfy (16) for all $t \geq 1$;

- $P_{t}^{0}, P_{t}^{1}$, and $P_{t}$ satisfy $(17)$ for all $t \geq 0$;

- the feasibility constraint in (4) is satisfied for all $t \geq 0$.

- the interest rate rule in (13) determines $i_{t}$; and

- labor markets clear

$$
\frac{A_{t} N_{t}}{\frac{1}{2}\left(\frac{P_{t}^{0}}{P_{t}}\right)^{-\varepsilon}+\frac{1}{2}\left(\frac{P_{t}^{1}}{P_{t}}\right)^{-\varepsilon}}=C_{t}+\left(S_{t+1}+Q_{t+1}\right) /(1-\delta)-S_{t}-Q_{t}
$$

In the equilibrium analysis below, I maintain the assumption that Joseph sets $B_{t}=$ $Q_{t}=0$ for $t \geq 2$ to mimic the flexible-price allocation's absence of storage after the famine's first year,

Given total storage, its decomposition between $S_{t+1}$ and $Q_{t+1}$ is of no consequence to any individual household. Nevertheless, Joseph might prefer public storage because setting $B_{1}>0$ and setting $Q_{1}$ to the resulting real goods accumulated can impact the equilibrium set through two channels. First, Joseph's accumulation of both real assets and offsetting nominal liabilities allows the fiscal theory of the price level to determine next period's price level, $P_{1}$. In turn, this requires Joseph's real cost of funds (the real return on nominal bonds) to equal the real return on his storage investments. In the liquidity traps proven to exist by Proposition 3, the real return on nominal bonds exceeds the cost of storage. Therefore, these are inconsistent with even a small amount of JQE. I summarize this first channel in the following

Proposition 5. If $B_{1}>0$, then in any equilibrium with nominal rigidities and $J Q E$,

$$
\frac{1+i_{0}}{\pi_{1}}=(1-\delta) .
$$


Furthermore, there exists no equilibrium with consumption and prices equal to those from an equilibrium with nominal rigidities proven to exist by Proposition 3.

Proof. To prove that Equation (28) must hold in an equilibrium with $B_{1}>0$, use (4) for year $0, Q_{1}=(1-\delta) B_{1} /\left(\left(1+i_{0}\right) P_{0}\right)$, to eliminate $Q_{1}$ from the same equation for year $1, B_{1} / P_{1}=Q_{1}$. Remove $B_{1}$ from the resulting equation and rearrange. For the second assertion, note that in the referenced equilibria we have

$$
1-\beta \frac{C_{0}}{C_{1}}(1-\delta)=\nu_{0}>0=1-\beta \frac{C_{0}}{C_{1}} \frac{1+i_{0}}{\pi_{1}},
$$

which contradicts Equation (28).

In theory, even a small amount of JQE can substitute for inflation-expectations management by other (unmodeled) means, such as the communications protocols of an inflation-targeting regime. In practice, its efficacy at this task depends on whether or not households expect the feasibility constraint (4) to hold in year 1 . In the language of Leeper (1991), Sims (1994), and Woodford (1994); Joseph follows an active fiscal policy. Its game-theoretic foundations are beyond the scope of this paper, but they could be developed following Bassetto (2002). If instead Joseph could follow a passive fiscal policy and recover any capital loss incurred from deflation by taxing households directly, then deflation might occur in equilibrium. In that case, nominal bonds' real rate of return would exceed the real rate of return on storage, so Proposition 5's conclusions would not hold. For this reason, JQE might best be delegated to a monetary authority without access to a reliable stream of tax revenues.

With this potentially important caveat in place, we can proceed to consider the second channel for JQE to influence the equilibrium set: Government wealth $\left(Q_{1}\right)$ places a floor on $C_{1}$. This in turn bounds $C_{0}$ from below and thereby eliminates confidence recessions with consumption beneath the bound. Unsurprisingly, this channel's efficacy depends on the magnitude of $B_{1}$.

To develop this in more detail, define

$$
\underline{C}_{0} \equiv(1-\delta)^{-1} \beta^{-1} C^{\star} \text { and } \underline{P}_{0} \equiv P_{0}\left(\underline{C}_{0}\right)
$$

These are the initial consumption and price level in the worst equilibrium of Proposition 4; which is the transitional equilibrium in Figure 3's IS curve. (The underlines 
indicate that these are lower bounds.) With this notation, we can state

Proposition 6. Define

$$
\underline{B}_{1} \equiv \beta \underline{C}_{0} \underline{P}_{0} \max \left\{1, \pi^{\star}(1-\delta) \underline{P}_{0}^{\phi}\right\}
$$

and

$$
\bar{B}_{1} \equiv \tilde{C}_{1} \frac{\max \left\{1, \pi^{\star}(1-\delta)\right\}}{1-\delta}
$$

For each $B_{1} \in\left[\underline{B}_{1}, \bar{B}_{1}\right]$, there exists a threshold $\bar{C}_{0}\left(B_{1}\right)$ for $C_{0} \in\left[\underline{C}_{0}, \tilde{C}_{0}\right]$ such that

1. $\bar{C}_{0}\left(\underline{B}_{1}\right)=\underline{C}_{0}$;

2. $\bar{C}_{0}\left(B_{1}\right)$ is strictly increasing in $B_{1}$;

3. $\bar{C}_{0}\left(\bar{B}_{1}\right)=\tilde{C}_{0}$;

4. there is no equilibrium with nominal rigidities and JQE with both the given value of $B_{1}$ and $C_{0}<\bar{C}_{0}\left(B_{1}\right)$; and

5. any equilibrium with nominal rigidities of Proposition 4 with $C_{0} \geq \bar{C}_{0}\left(B_{1}\right)$ has a corresponding equilibrium with nominal rigidities and JQE with the given value of $B_{1}$ and the same sequences for $C_{t}$ and $N_{t}$;

Appendix A: contains Proposition 6's proof. To summarize, the two channels for JQE allow Joseph to destroy all liquidity traps and confidence recessions by setting $B_{1}=\bar{B}_{1}$. A slightly smaller balance-sheet expansion eliminates some confidence recessions, but leaves those with $C_{0}$ slightly below $\tilde{C}_{0}$ in place. Finally, a very small balance sheet expansion eliminates liquidity traps by equating nominal bonds' real return with that of storage, but it leaves room for households to coordinate on a confidence recession with too little saving. All of these policies draw a vertical line at $\bar{C}_{0}\left(B_{1}\right)$ on the IS curve of Figure 3 , which eliminates all equilibria to its left. Furthermore, JQE requires no commitment to time-inconsistent interest-rate or balance-sheet policies.

The hypothesis that the decomposition of national wealth into private and government hands is irrelevant for individual decisions provides the point of departure for most theoretical discussions of QE. For example, Eggertsson and Woodford (2003) "argue that the possibility of expanding the monetary base through central 
bank purchases of a variety of types of assets does little if anything to expand the set of feasible paths for inflation and real activity that are consistent with equilibrium under some (fully credible) policy commitment." ${ }^{15}$ Nothing in this paper contradicts this assertion. Here, the division of total national wealth into that held directly by the public and that held by Joseph on the public's behalf is irrelevant for individual households' decisions given prices, interest rates, and other macroeconomic variables. Nevertheless, JQE potentially improves economic outcomes by shrinking the set of feasible paths that are consistent with equilibrium.

Previous models of liquidity traps with policy-relevant QE have either featured an explicit role for money (Auerbach and Obstfeld, 2005), frictions that impede private borrowing and lending (Cúrdia and Woodford, 2011; Gertler and Karadi, 2011), financial markets segmented by asset maturity (Chen, Cúrdia, and Ferrero, 2012), or limited commitment that can be overcome somewhat by manipulating the maturity structure of the monetary authority's balance sheet (Bhattari, Eggertsson, and Gafarov, 2014). In all of those approaches, QE can potentially improve a given equlibrium outcome. In contrast, JQE has no impact on an equilibrium which would have occurred anyways. Instead, it guides households' expectations towards the flexible-price allocation. The quality of that guidance depends on how close $B_{1}$ is to $\bar{B}_{1} \cdot{ }^{16}$

With segmented financial markets, the monetary authority can influence assets' relative prices by changing their relative supplies. Accordingly, empirical investigations of QE have concentrated on measuring its impact on asset prices. The present economy has unified financial markets, but it would be incorrect to conclude from that fact alone that JQE does not influence asset prices. When it is successful, in the sense that it eliminates a confidence recession that would have otherwise occurred, the expected risk-free interest rate from year 1 to year 2 falls because $C_{1}$ rises while all $C_{2}$ remains unchanged. Although Eggertsson and Woodford (2003) emphasize that forward-guidance can expand current economic activity by reducing long-dated real interest rates, the analogous reduction in this model is a consequence of such an economic expansion; not its cause.

\footnotetext{
${ }^{15}$ See Page 143 of Eggertsson and Woodford (2003).

${ }^{16}$ Farmer and Zabczyk (2016) characterize an unconventional monetary policy, qualitative easing that increases the riskiness of central bank assets, which can potentially improve outcomes (in part) by resolving equilibrium indeterminacy. This channel through which the public accumulation of private assets can improve allocations complements those explored in the present paper.
} 


\section{An Open Economy Interpretation}

Although I have developed the analysis of JQE in a closed economy, one may interpret the model's storage technology as a representation of using international trade to achieve intertemporal substitution. For this, suppose that the economy is small relative to a large foreign sector. The aggregate good can be shipped either to or from the foreign sector at the iceberg transportation cost $\tau$. The real rate of return available in the foreign sector is $r^{f}$. Then, if we define $\delta$ with

$$
1-\delta=(1-\tau)^{2}\left(1+r^{f}\right)
$$

we can interpret storage as shipping aggregate goods abroad, selling them, investing the proceeds in foreign bonds, and repatriating the proceeds in the next year by shipping the aggregate good back home. In this interpretation, the restriction that $S_{t} \geq 0$ should be interpreted as a limit on uncollateralized international borrowing. The absence of a non-negativity constraint on bond purchases embodies the assumption that domestic households can borrow and lend freely amongst themselves.

If we suppose that the foreign sector uses a currency subject to no inflation with a price-level of 1 for the same aggregate good, then we can introduce a market for the exchange of home and foreign currencies. If the aggregate good is exported, then the price of foreign currency in units of home currency is $e_{t}=P_{t} /(1-\tau)$. If instead the aggregate good is imported, then $e_{t}=P_{t}(1-\tau)$. In the absence of international trade, equilibrium only requires that $e_{t} \in\left[P_{t}(1-\tau), P_{t} /(1-\tau)\right]$. One might conclude that JQE depreciates the home currency if it eliminates an equilibrium with $S_{1}=0$ and $e_{0}<P_{0} /(1-\tau)$ that otherwise would have occurred. However, such a depreciation is not logically necessary and so cannot be said to cause the home country's initial current-account surplus.

In the open economy, JQE mimics the monetary mechanics of a sterilized competitive devaluation (trade interest-bearing domestic liabilities for foreign assets). This paper is not the first to notice the strong resemblance between sterilized interventions and quantitative easing. For example, Rajan (2014) labels such interventions (tongue in cheek) as "Quantitative External Easing" (QEE). He reports

Indeed, some advanced economy central bankers have privately expressed their worry to me that QE “works" primarily by altering exchange rates, 
which makes it different from QEE only in degree rather than in kind. ${ }^{17}$

It is inconceivable that these anonymous central bankers had JQE in mind when confiding with Rajan, but from this model's perspective JQE and QEE are indeed cut from the same cloth. Nevertheless, changes to the real exchange rate play no role in JQE's effectiveness. Instead, it works by coordinating home-country households' savings decisions and thereby enabling them to substitute consumption intertemporally using international trade. As noted in the introduction, the foreign sector's initial current-account deficit and its eventual reversal are not side effects of JQE. Together, they are its goal.

If the foreign sector itself also faces a Keynesian shortfall in aggregate demand, then JQE can easily turn into a beggar-thy-neighbor affair. However, without foreign-sector inefficiencies it results in a Pareto-efficient allocation of world resources. This suggests that the international monetary policy cooperation advocated by Rajan (2014) can indeed improve worldwide macroeconomic performance when these two possibilities can be distinguished. Further investigation of this point within the framework of Korinek (2016) is certainly worthwhile, but it lies beyond this paper's scope.

\section{Conclusion}

When prices are flexible, a shock to the demand for real assets leads households to accumulate goods in storage for later consumption, just as in the biblical Joseph story. Price stickiness can disrupt this outcome and send the economy into a recession even when nominal bonds' real return is consistent with the flexible-price allocation. In this sense, conventional interest-rate policy and forward guidance that manipulates inflation expectations cannot necessarily guide the economy to its potential. QE that purchases real assets, JQE, can fill this policy gap. JQE puts a floor on future national wealth and consumption, and the expectation of high future consumption raises current consumption and output. Furthermore, JQE requires no commitment to a time-inconsistent interest-rate policy. Ironically, the full solution to the "paradox of thrift" coordinates an increase in savings.

This paper's model of JQE endowed households' and the public sector with the

${ }^{17}$ Page 6 of Rajan (2014) 
same storage technology. Appendix B: shows how the public sector's storage can be reinterpreted as the purchases of private assets backed by storage. Such a simple environment abstracts from a potentially substantial practical difficulty with this policy, choosing which assets to purchase. To the extent that implementing the flexible-price equilibrium requires accumulating assets issued by foreigners, this problem can be contained by confining purchases to foreign sovereign debt. However, if implementation requires purchasing heterogeneous assets issued by heterogenous domestic agents, such public portfolio choices inevitably have distributional consequences and so will be subject to political influence. To the extent possible, this suggests mitigating such influence by delegating JQE to an independent central bank.

The present paper should not be cast as a positive analysis of major central banks' QE, since their purchases have focused on their own sovereigns' debts. However, the analysis of JQE might illuminate the economic performance of small open economies with large foreign currency reserves. Take for example Joseph's direct successor, the Bank of Israel. At the end of 2015, it held over $\$ 91$ billion of foreign reserves. Israel's capital account at the same time was approximately $\$ 69$ billion; while her nominal GDP for that year was approximately $\$ 296$ billion. ${ }^{18}$ In light of this paper's analysis, such large holdings of foreign assets might be interpreted as a means of anchoring expectations of future wealth and thereby preventing the collapse of current savings and consumption. From this perspective, the Bank of Israel's foreign reserve policy extends a truly ancient policy tradition.

\footnotetext{
${ }^{18}$ All figures come from Bank of Israel publications. I converted nominal GDP in sheqels into dollars using the average effective nominal exchange rate for 2015 reported by the B of I, 3.8869 sheqels $/ \$$
} 


\section{Appendix A: Proof of Proposition 6}

Define

$$
\Upsilon(C, B) \equiv \beta(1-\delta) C-\frac{(1-\delta) B}{P_{0}(C) \max \left\{1,(1-\delta) \pi^{\star} P_{0}(C)^{\phi}\right\}}
$$

This function is strictly increasing in $C$ and strictly decreasing in $B$. Furthermore, it is straightforward to show by substitution that

$$
\Upsilon\left(\underline{C}_{0}, \underline{B}_{1}\right)=0 \text { and } \Upsilon\left(\tilde{C}_{1}, \bar{B}_{1}\right)=0 \text {. }
$$

Therefore, we may define $\bar{C}_{0}\left(B_{1}\right)$ implicitly from $\Upsilon\left(\bar{C}_{0}\left(B_{1}\right), B_{1}\right)=0$ and conclude that it is strictly increasing in $B_{1}$. This establishes the proposition's first three enumerated conclusions.

Proceeding to the fourth enumerated conclusion, presume the opposite. That is, such an equilibrium exists. Since $P_{0}\left(C_{0}\right)$ is strictly increasing, we know that $P_{0}<$ $P_{0}\left(\bar{C}_{0}\left(B_{1}\right)\right)$ and $1+i_{0} \leq \max \left\{1,(1-\delta) \pi^{\star} P_{0}\left(\bar{C}_{0}\left(B_{1}\right)\right)^{\phi}\right\}$. These results, the feasibility constraint (4), and the definition of $\bar{C}_{0}\left(B_{1}\right)$ together imply that $Q_{1}>\beta(1-\delta) \bar{C}_{0}\left(B_{1}\right)$. By assumption $\bar{C}_{0}\left(B_{1}\right)>C_{0}$ in this equilibrium; so we have $Q_{1}>\beta(1-\delta) C_{0}$. From Proposition 5 and the Euler equations for optimal private bond purchases and optimal private storage $((8)$, and $(9))$, we know that $C_{1}=\beta(1-\delta) C_{0}$. Putting these results together, we conclude that $Q_{1}>C_{1}$.

Since $Q_{1}>C_{1}$, the labor-market clearing condition for period 1 requires that $S_{2}>0$. Note that the upper bound on the return to storage in (3) can be rewritten as $1>\beta(1-\delta) \tilde{C}_{1} / \tilde{C}_{2}$. Since $C_{0}<\bar{C}_{0}\left(B_{1}\right) \leq \tilde{C}_{0}$, we know that $C_{1}<\tilde{C}_{1}$. Furthermore, the optimal labor-supply condition in (7) and the complementary slackness conditions $v_{2} \geq 0, N_{2} \geq 0$, and $v_{2} N_{2}=0$ together require that $C_{2} \geq \tilde{C}_{2}=C^{\star}$. Therefore, we can conclude that $1>\beta(1-\delta) C_{1} / C_{2}$. This combined with the Euler equation for optimal private storage implies that $\nu_{1}>0$. The complementary-slackness conditions associated with the non-negativity constraint on $S_{2}$ require that $S_{2} \nu_{1}=0$, but we now know that $S_{2} \nu_{1}>0$. This contradicts the supposition of an equilibrium with $C_{0}<\bar{C}_{0}\left(B_{1}\right)$, establishing the fourth labelled conclusion.

All that remains to be demonstrated is the Proposition's final labelled conclusion. Begin this by adopting the original equilibrium's sequences for $C_{t}, N_{t}, W_{t}, P_{t}^{0}$, $P_{t+1}^{1}, P_{t}, D_{t}$, and $i_{t}$. Then, set $Q_{1}=(1-\delta) B_{1} /\left(P_{0}\left(1+i_{0}\right)\right)$. Since $C_{0} \geq \bar{C}_{0}\left(B_{1}\right)$, $Q_{1} \leq \beta(1-\delta) \bar{C}_{0}\left(B_{1}\right) \leq C_{1}$. Therefore, we can set $S_{1}=C_{1}-Q_{1}>0$. To complete 
the candidate equilibrium, set $S_{t}=B_{t}=Q_{t}=0$ for all $t \geq 2$. The sequences for $C_{t}, N_{t}, B_{t+1}$, and $S_{t+1}$ solve the household's utility maximization problem given the sequences for $D_{t}, W_{t}, P_{t}$, and $i_{t}$; because the household is indifferent between directly accumulating $C_{1}$ and indirectly doing so by purchasing bonds with the storage technology's real rate of return. Firms' original pricing decisions remain optimal; and $B_{t+1}, Q_{t+1}$, and $i_{t}$ satisfy (4). Therefore, the candidate is indeed an equilibrium.

\section{Appendix B: Convex Storage Costs}

This appendix replaces the linear storage technology employed in the text with a concave technology that is represented by a convex cost function. To simplify the accounting of profits arising from these scarce storage opportunities, I take the storage technology out of the households' hands and add banks to the model. There is a unit mass of banks, each of which can produce $S$ units of the aggregate good next year by investing $\Xi(S)$ units of the aggregate good in the storage technology. This input-requirement/cost function is twice differentiable everywhere, and satisfies $\Xi(0)=0, \Xi^{\prime}(0)>0$, and $\Xi^{\prime \prime}(S)>0$. As did the households' investments in the model's text, banks' investments must satisfy $S_{t+1} \geq 0$. To interpret this investment as productive capital accumulation, suppose that a second capital-intensive production technology exists alongside the labor-intensive technology used in the text. A capital stock of $K$ employed by a differentiated-product firm yields $f(K)$ units of that product, where the production function $f(\cdot)$ is strictly increasing and concave. Producing $S$ units of the aggregate good with this technology in year 1 (which will have all differentiated product prices equal to each other) requires $f^{-1}(S)$ units of capital. If capital fully depreciates after one year, the.n we can represent this technology in the current environment by setting $\Xi(S) \equiv f^{-1}(S)$. It is possible to carry out this analysis with capital and labor complementary in production, but this extension complicates matters with a required accounting for future labor supply when calculating the return to investment.

With a convex cost of storage, the analogue to (3) is

$$
\left(\frac{\beta}{\Xi^{\prime}(0)}\right)^{2} \frac{A^{H}}{A^{L}}<1 .
$$


This guarantees that $\tilde{S}_{t}=0$ for all $t \geq 2$. This condition could be weakened at a small expositional cost. The aggregate resource constraint with flexible prices and this technology is

$$
A_{t} N_{t}=C_{t}+\Xi\left(S_{t+1}\right)-S_{t}
$$

Banks finance their inputs by issuing nominal bonds. In the next year, they use the proceeds from selling the storage technology's output to retire them. Any remaining proceeds are returned to the representative household as dividends. Just like those of the economy's firms, these dividends can be negative because banks face unlimited liability. Banks in year $t$ choose $S_{t+1}$ to maximize real dividends in period $t+1, S_{t+1}-\Xi\left(S_{t+1}\right)\left(1+i_{t}\right) / \pi_{t+1}$. If we use $\omega_{t}$ to denote the non-negativity constraint's Lagrange multiplier, then the first-order necessary condition for this problem is

$$
1+\omega_{t}=\Xi^{\prime}\left(S_{t+1}\right)\left(1+i_{t}\right) / \pi_{t+1}
$$

If $\omega_{t}>0$, then the cost of storage investment exceeds its benefit, so $S_{t+1}=0$.

\section{The Flexible-Price Allocation}

With the text's linear storage technology, famines were classified into severe and mild depending on whether or not the flexible price allocation set $\tilde{S}_{1}>0$. With the more general convex cost of storage, it is useful to divide famines into three categories; severe, intermediate, and mild. In a severe famine, $\tilde{S}_{1}>0$ and $\tilde{N}_{1}=0$. That is the household saves in order to take a vacation during the famine's first

year. In an intermediate famine, $\tilde{S}_{1}>0$ but $\tilde{N}_{1}>0$. The household uses storage to reallocate hours worked from year 1 to year 0 and thereby save on its utility cost, but the consumption profile is the same as that in a mild famine; when $S_{1}=0$ and the storage technology is irrelevant.

\section{I.1 Mild Famines}

To define a mild famine, replace (12) with

$$
\frac{\beta A^{H}}{A^{L}} \leq \Xi^{\prime}(0)
$$

When this holds, the flexible-price allocation is exactly the same as that in the text. 


\section{I.2 Severe Famines}

In a severe famine, the marginal cost of increasing storage at $C^{\star}$ (as defined in the text) is less than its benefit when $C_{1}=C^{\star}$. That is

$$
\frac{\beta A^{H}}{A^{L}}>\Xi^{\prime}\left(C^{\star}\right)
$$

It is straightforward to combine this with (A1) to demonstrate that $\tilde{S}_{1}=\tilde{C}_{1}>C^{\star}$. With this, combining banks' profit maximization condition with (8) gives

$$
\beta \tilde{C}_{0}=\tilde{C}_{1} \Xi^{\prime}\left(\tilde{C}_{1}\right) .
$$

This implicitly defines $\tilde{C}_{1}$. Aside from this modification to $\tilde{C}_{1}$ and the attendant change to $\tilde{N}_{0}$, the flexible-price allocation with a severe famine is the same as that in the text.

\section{I.3 Intermediate Famines}

With the linear technology of the text, $\Xi^{\prime}(0)=\Xi^{\prime}\left(C^{\star}\right)$, so either (A3) or (A4) must hold. The assumption that $\Xi^{\prime \prime}(S)>0$ creates a third case.

$$
\Xi^{\prime}(0)<\frac{\beta A^{H}}{A^{L}} \leq \Xi^{\prime}\left(C^{\star}\right)
$$

This says that the marginal benefit of storage when $C_{0}=\tilde{C}_{0}$ and $C_{1}=C^{\star}$ exceeds its marginal cost when there is no storage but is less than its marginal cost when storage equals or exceeds $C^{\star}$. In this case, the flexible-price allocation's consumption profile equals that from a mild famine. To retrieve $\tilde{S}_{1}$, use banks' profit maximization condition.

$$
\frac{\beta \tilde{C}_{0}}{\tilde{C}_{1}}=\Xi^{\prime}\left(\tilde{S}_{1}\right)
$$

With $\tilde{S}_{1}$ in hand, the resource constraint immediately yields $\tilde{N}_{0}$ and $\tilde{N}_{1}$. All of the allocation's other quantities equal those from a mild famine. 


\section{Equilibria with Nominal Rigidities}

Much of the text's analysis of equilibria with nominal rigidities applies to the model with $\Xi^{\prime \prime}(S)>0$ with little or no modification. Section 4.1's characterization of the Phillips curve has nothing to do with the storage technology, and adapting the flexible-price allocation replicator of Section 4.2 to this economy is a simple exercise. As in the text, adding nominal rigidities introduces a possible production inefficiency. This manifests itself in the economy's labor market clearing condition.

$$
\frac{A_{t} N_{t}}{\frac{1}{2}\left(\frac{P_{t}^{0}}{P_{t}}\right)^{-\varepsilon}+\frac{1}{2}\left(\frac{P_{t}^{1}}{P_{t}}\right)^{-\varepsilon}}=C_{t}+\Xi\left(S_{t+1}\right)-S_{t} .
$$

\section{II.1 Mild Famines}

With this change, the analogue to Proposition 1 is

Proposition A1. Suppose that $\beta A^{H} / A^{L}<\Xi^{\prime}(0)$ and select $\pi_{1}$ that satisfies (22). Then there exists a equilibrium in which $\pi_{t}$ equals the given value of $\pi_{1}$ for $t=1$, $S_{t+1}=0$ for all $t \geq 0, C_{0}<\tilde{C}_{0}$ and $C_{t}=\tilde{C}_{t}$ for all $t \geq 1$.

Proof. Consider the sequences for $C_{t}, S_{t}, N_{t}$, and $\pi_{t}$ constructed before the statement of Proposition (1) in the text. The only requirement that the proposed equilibrium does not satisfy by construction is (A2). To verify that the value of $\omega_{0}$ required to satisfy this is not negative, use the upper bound for $\pi_{1}$ from (22), the Proposition's first stated assumption, and the non-negativity of $i_{0}$ to get

$$
\frac{1+i_{0}}{\pi_{1}} \Xi^{\prime}(0)>\frac{1+i_{0}}{\beta A^{H} / A^{L}} \Xi^{\prime}(0)>1 .
$$

So $\omega_{0}=\frac{1+i_{0}}{\pi_{1}} \Xi^{\prime}(0)-1>0$.

\section{II.2 Intermediate Famines}

Just as with severe famines in the text, the equilibrium outcomes that are possible with a mild famine remain possible with an intermediate or severe famine. The following Proposition (the analogue to Proposition 3 in the text) formalizes this. 
Proposition A1.1. Suppose that $\Xi^{\prime}(0)<\beta A^{H} / A^{L}$ and select

$$
\pi_{1} \in\left(\varsigma \Xi^{\prime}(0) \frac{\beta A^{H}}{A^{L}}, \Xi^{\prime}(0)\right] .
$$

Then there exists an equilibrium with the consumption, hours worked, and storage sequences from the equilibrium of Proposition A1 with the same value of $\pi_{1}$.

Proof. The construction in Proposition 3 with $(1-\delta)^{-1}$ in $(24)$ replaced by $\Xi^{\prime}(0)$ goes through without further modification if $\Xi^{\prime}(0)<\beta A^{H} / A^{L}$. To verify that the accompanying value value of $\omega_{0}$ required to satisfy (A2) is not negative, use the upper bound for $\pi_{1}$ and the zero lower bound on $i_{0}$ to get

$$
\frac{1+i_{0}}{\pi_{1}} \Xi^{\prime}(0)>1+i_{0} \geq 1
$$

So $\omega_{0}=\frac{1+i_{0}}{\pi_{1}} \Xi^{\prime}(0)-1>0$.

With an intermediate famine, a type of recessionary equilibrium arises that does not appear in the model of the text, a storage recession. To construct one, set $C_{1}=\tilde{C}_{1}$ and select

$$
C_{0} \in\left[\frac{\tilde{C}_{1} \Xi^{\prime}(0)}{\beta}, \tilde{C}_{0}\right]
$$

The lower end of this interval is the largest $C_{0}$ from an equilibrium of Proposition A1.1, and this exceeds $\varsigma \tilde{C}_{0}$. Therefore, we can apply Section 4.1 to find values for $P_{0}^{0}, P_{0}$, and $W_{0}$ consistent with any such $C_{0},(7),(15)$, and (17). Continuing, combine (8) with (A2) to yield

$$
\frac{\beta C_{0}}{\tilde{C}_{1}}=\Xi^{\prime}\left(S_{1}\right)
$$

This implicitly defines $S_{1}$ as an increasing function of $C_{0}$. This can be no greater than $\tilde{S}_{1}$ because $C_{0} \leq \tilde{C}_{0}$. To complete the equilibrium allocation's construction, set $C_{t}=\tilde{C}_{t}, S_{t}=0$, and $N_{t}=\tilde{N}_{t}$ for $t \geq 2$.

To get this equilibrium allocation's accompanying nominal interest rates and prices, plug $\pi_{0} \equiv \pi^{\star} P_{0}$ into (13) to get $i_{0}$; and use this and the real interest rate implied by $S_{1}$ to set $\pi_{1}$.

$$
\pi_{1}=\left(1+i_{0}\right) \Xi^{\prime}\left(S_{1}\right)
$$




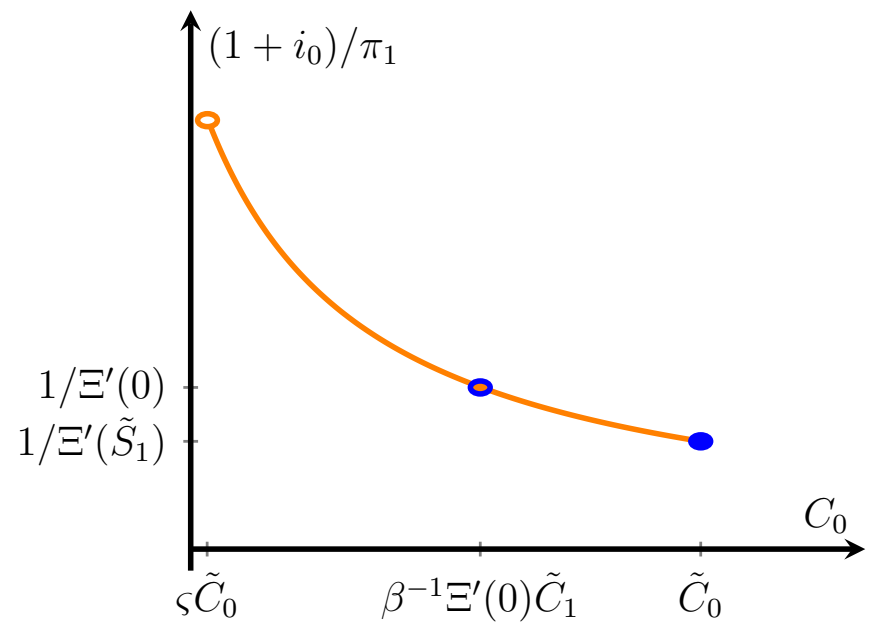

Figure A1: The IS Curve with an Intermediate Famine

Equations (13) and (21) then give $i_{t}$ and $\pi_{t}$ for $t \geq 2$. I summarize this with a

Proposition A2. Suppose that $\beta A^{H} / A^{L}>\Xi^{\prime}(0)$, and select $C_{0}$ from the interval in (A9). Then there exists an equilibrium with the given value of $C_{0}$ and $C_{1}=\tilde{C}_{1}$. Furthermore, $S_{1}$ is strictly increasing with the chosen value for $C_{0}$.

Economically, a storage recession occurs when a high real interest rate (supported by a lack of real investment) resolves the fundamental multiplicity with a low value of $C_{0}$.

Figure A1 plots the IS curve for the case with an intermediate famine. As in Figure 3 , the empty orange circle indicates the limit of the liquidity trap equilibria as $C_{0}$ is driven to its lower bound of $\varsigma \tilde{C}_{0}$, and the solid blue circle denotes the equilibrium that implements the flexible-price allocation. For real interest rates above $1 / \Xi^{\prime}(0)$, the economy is in a liquidity trap, and below that but above $1 / \Xi^{\prime}\left(\tilde{S}_{1}\right)$ it is in a storage recession. The blue circle filled with orange is the transitional equilibrium that falls into both of these categories.

\section{II.3 Severe Famines}

Since both Proposition 1.1 and Proposition 2 apply when the anticipated famine is severe, either a liquidity trap or a storage recession is possible in this case. To 
construct a confidence recession, begin by selecting

$$
C_{1} \in\left[C^{\star}, \tilde{C}_{1}\right)
$$

Then set $S_{1}=C_{1}$ and $C_{0}=\beta^{-1} C_{1} \Xi^{\prime}\left(C_{1}\right)$. Given $C_{0}$, retrieve $P_{0}$ from the Phillips curve and then get $W_{0}$ and $P_{0}^{0}$ from (7) and (15). The labor market clearing condition in (A8) then determines $N_{0}$, and $N_{1}=0$. The interest-rate rule in (13) gives $i_{0}$; and setting $\pi_{1}=\left(1+i_{0}\right) \Xi^{\prime}\left(C_{1}\right)$ ensures that both (8) and (A2) are satisfied. For $t \geq 2$; setting $S_{t}=0, C_{t}=\tilde{C}_{t} ; N_{t}=\tilde{N}_{t}, \pi_{t}$ using (21), and $i_{t}$ using (13) completes the equilibrium construction. The upper bound on the return to storage in (A1) ensures that this corner solution for $S_{2}$ maximizes bank profits given $C_{0}$ and $C_{1}$, because

$$
\tilde{C}_{1}=\frac{\beta \tilde{C}_{0}}{\Xi^{\prime}\left(\tilde{C}_{1}\right)}<\frac{\beta \tilde{C}_{0}}{\Xi^{\prime}(0)}
$$

and therefore

$$
\frac{1+i_{1}}{\pi_{2}} \Xi^{\prime}(0)=\frac{\beta^{-1} C_{2}}{C_{1}} \Xi^{\prime}(0)=\frac{\beta^{-1} C^{\star}}{C_{1}} \Xi^{\prime}(0)>\frac{\beta^{-1} C^{\star}}{\tilde{C}_{1}} \Xi^{\prime}(0)>\left(\frac{\Xi^{\prime}(0)}{\beta}\right)^{2} \frac{A^{L}}{A^{H}}>1 .
$$

With this construction in hand, I can state the following analogue to Proposition 4.

Proposition A3. Suppose that $\Xi^{\prime}\left(C^{\star}\right)<\beta A^{H} / A^{L}$, and select $C_{1}$ from the interval in (A11). Then there exists an equilibrium with the given value of $C_{1}$ and $C_{0}<\tilde{C}_{0}$. In this equilibrium, $C_{0}$ and $N_{0}$ are strictly increasing with the chosen value for $C_{1}$.

Figure A2 plots the IS curve for this model that is the analogue of that in Figure 3. As in the earlier IS curves, the empty orange circle indicates the limit attained from driving $C_{0}$ to its lower bound, and the solid blue dot marks the equilibrium that implements the flexible-price allocation. Blue circles are at the two transitional equilibria. The left equilibrium is both a liquidity trap and a storage recession, while the right one is both a storage recession and a confidence recession. The IS curve is differentiable at the first one but not at the second. Unlike that in Figure 3, this IS curve has no horizontal segment. The discussion in the text emphasized the fact that Joseph might not be able to guide the economy to the flexible-price allocation even if he (somewhat magically) could set $\left(1+i_{0}\right) / \pi_{1}$ directly. Here with $\Xi^{\prime \prime}(\cdot)>0$, such extremely-effective guidance of real interest rates does indeed destroy all recessionary equilibria. Of course, the sensitivity of economic outcomes 


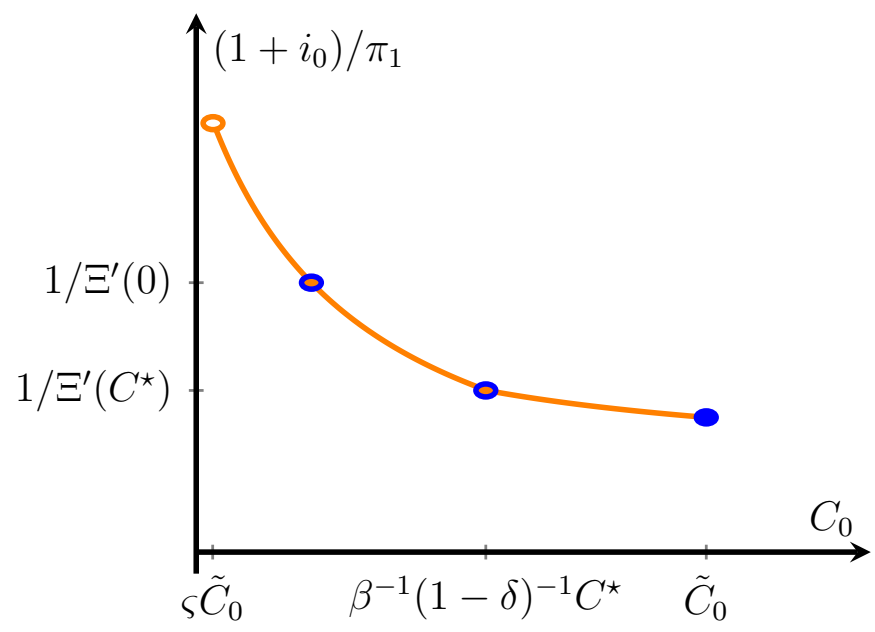

Figure A2: The IS Curve with a Severe Famine

with respect to $\pi_{1}$ depends inversely on $\Xi^{\prime \prime}(\cdot)$. If this is very small, then the IS curve is nearly horizontal and very small changes in $\pi_{1}$ can have large impacts on $C_{0}$. To the extent that actual central bankers can only influence $\pi_{1}$ imprecisely and indirectly, the ability of JQE to eliminate recessionary outcomes remains of interest.

\section{Josephean Quantitative Easing}

In the text, Joseph invested directly in the storage technology. Here, banks make this investment decision; so the specification of JQE must be suitably modified. Joseph issues nominal bonds with nominal redemption value $B_{1}$ and uses the proceeds to make loans to banks at the same nominal interest rate. Banks invest the proceeds of their borrowing, both from Joseph and from the private sector, and repay the loans in the next period with the proceeds of the storage technology. Since $\Xi^{\prime \prime}(\cdot)>0$, the banks will have profits following a positive investment in storage. These are returned to the representative household as dividends.

Of course, no single household nor any individual bank cares about the fraction of a given investment in storage that Joseph intermediates. However, it is relevant for the equilibrium analysis because Joseph's intermediation choice places a lower bound on total borrowing.

The text separated the influence of JQE into two channels, which corresponded to the elimination of liquidity traps by setting $B_{1}>0$ and the elimination of con- 
fidence recessions by setting $B_{1}=\bar{B}_{1}$. The presence of storage recessions (which requires $\Xi^{\prime \prime}(\cdot)>0$ ), makes these two channels less distinct. Therefore, I place the results analogous to Propositions 5 and 6 for storage recessions within the following single proposition. At the same time, the analysis of JQE in intermediate famines is sufficiently distinct from that in severe famines to merit its own proposition. Therefore, this appendix concludes with the analogous proposition and its proof for the case with a severe famine.

Proposition A4. Suppose that $\Xi^{\prime}(0)<\beta A^{H} / A^{L} \leq \Xi^{\prime}\left(C^{\star}\right)$. For each

$$
B_{1} \in\left(0, \Xi^{-1}\left(\tilde{S}_{1}\right) \max \left\{1, \pi^{\star} / \Xi^{\prime}\left(\tilde{S}_{1}\right)\right\}\right]
$$

there exists a threshold $\bar{C}_{0}\left(B_{1}\right) \in\left[\beta^{-1} C^{\star} \Xi^{\prime}(0), \tilde{C}_{0}\right]$ such that

1. $\lim _{B \downarrow 0} \bar{C}_{0}(B)=\beta^{-1} C^{\star} \Xi^{\prime}(0)$,

2. $\bar{C}_{0}\left(B_{1}\right)$ is strictly increasing in $B_{1}$,

3. $\bar{C}_{0}\left(\Xi^{-1}\left(\tilde{S}_{1}\right) \max \left\{1, \pi^{\star} / \Xi^{\prime}\left(\tilde{S}_{1}\right)\right\}\right)=\tilde{C}_{0}$,

4. there is no equilibrium with $C_{0}<\bar{C}_{0}\left(B_{1}\right)$; and

5. any equilibrium of Proposition $A 2$ with $C_{0}>\bar{C}_{0}\left(B_{1}\right)$ has a corresponding equilibrium with the given value of $B_{1}$ and the same sequences for $C_{t}$ and $N_{t}$.

Proof. Define

$$
\Upsilon(C, B)=\beta \frac{C}{\tilde{C}_{1}}-\Xi^{\prime}\left(\Xi^{-1}\left(\frac{B}{P_{0}(C) \max \left\{1, \pi^{\star} P_{0}(C)^{\phi} / \Xi^{\prime}\left(\tilde{S}_{1}\right)\right\}}\right)\right)
$$

Verifying that $\Upsilon(C, B)$ is strictly increasing in $C$ is straightforward, so we can define $\bar{C}_{0}\left(B_{1}\right)$ implicitly with $\Upsilon\left(\bar{C}_{0}\left(B_{1}\right), B_{1}\right)=0$. The second enumerated result follows from the demonstration that $\Upsilon(C, B)$ also strictly decreases with $B$. Direct substitution establishes the first and third enumerated results.

To prove the fourth assertion, suppose that it is not true. That is, there exists an equilibrium with $C_{0}<\bar{C}_{0}\left(B_{1}\right)$. This requires $P_{0}<P_{0}\left(\bar{C}_{0}\left(B_{1}\right)\right)$ and $1+i_{0} \leq$ 
$\max \left\{1, \pi^{\star} P_{0}\left(\bar{C}_{0}\left(B_{1}\right)\right)^{\phi} / \Xi^{\prime}\left(\tilde{S}_{1}\right)\right\}$. Since the real purchasing power of the fixed nominal bond issuance $B_{1}$ decreases with both $P_{0}$ and $i_{0}$, we can conclude that

$$
S_{1}>\Xi^{-1}\left(\frac{B_{1}}{P_{0}\left(\bar{C}_{0}\left(B_{1}\right)\right) \max \left\{1, \pi^{\star} P_{0}\left(\bar{C}_{0}\left(B_{1}\right)\right)^{\phi} / \Xi^{\prime}\left(\tilde{S}_{1}\right)\right\}}\right)
$$

Therefore

$$
\Xi^{\prime}\left(S_{1}\right)>\Xi^{\prime}\left(\Xi^{-1}\left(\frac{B_{1}}{P_{0}\left(\bar{C}_{0}\left(B_{1}\right)\right) \max \left\{1, \pi^{\star} P_{0}\left(\bar{C}_{0}\left(B_{1}\right)\right)^{\phi} / \Xi^{\prime}\left(\tilde{S}_{1}\right)\right\}}\right)\right)=\frac{\beta \bar{C}_{0}\left(B_{1}\right)}{\tilde{C}_{1}}
$$

Banks' profit maximization and $S_{1}>0$ require that $\Xi^{\prime}\left(S_{1}\right)=\pi_{1} /\left(1+i_{0}\right)$; and the Euler equation for optimal household bond purchases requires that $\pi_{1} /\left(1+i_{0}\right)=$ $\beta C_{0} / C_{1}$. Therefore, we conclude that

$$
\frac{C_{0}}{C_{1}}>\frac{\bar{C}_{0}\left(B_{1}\right)}{\tilde{C}_{1}}
$$

By assumption, $C_{0}<\bar{C}_{0}\left(B_{1}\right)$, so this requires that $C_{1}<\tilde{C}_{1}$. Since $\tilde{C}_{1}=C^{\star}$, the non-negativity constraint on optimal labor supply in year 1 requires that $C_{1} \geq \tilde{C}_{1}$ in any equilibrium. Therefore, the supposition of an equilibrium with $C_{0}<\bar{C}_{0}\left(B_{1}\right)$ must be incorrect.

The final enumerated result's proof exactly parallels the analogous proof for Proposition 5.

The characterization of JQE with a severe famine employs the following Lemma. Lemma A1. In any equilibrium with $C_{0} \leq \tilde{C}_{0}, S_{2}=0$.

Proof. Suppose first that $S_{1}>0$ and $S_{2}>0$. From the first-order conditions for the household's choice of bonds and banks' profit maximization in period 0 we have

$$
C_{1}=\frac{\beta C_{0}}{\Xi^{\prime}\left(S_{1}\right)}<\frac{\beta \tilde{C}_{0}}{\Xi^{\prime}(0)}
$$

Futhermore, the non-negativity constraint on $N_{2}$ requires that $C_{2} \geq C^{\star}$. Therefore, the first-order condition for the household's optimal choice of bonds in period 2 yields

$$
\frac{1+i_{1}}{\pi_{2}} \Xi^{\prime}\left(S_{2}\right)=\frac{\beta^{-1} C_{2}}{C_{1}} \Xi^{\prime}\left(S_{2}\right) \geq \frac{\beta^{-1} C^{\star}}{\beta \tilde{C}_{0} / \Xi^{\prime}(0)} \Xi^{\prime}\left(S_{1}\right)>\left(\frac{\Xi^{\prime}(0)}{\beta}\right)^{2} \frac{A^{L}}{A^{H}}>1 .
$$


Here, the final inequality comes from (A1). This contradicts the first-order condition for banks' profit maximization with $S_{2}>0$, so the supposition that both $S_{1}>0$ and $S_{2}>0$ must be false.

Suppose instead $S_{1}=0$ and $S_{2}>0$, so the non-negativity constraint on $N_{1}$ requires that $C_{1}=C^{\star}$. Furthermore, the non-negativity constraint on $N_{2}$ requires that $C_{2} \geq C^{\star}$. Therefore, we have

$$
\frac{1+i_{1}}{\pi_{2}} \Xi^{\prime}\left(S_{2}\right)=\frac{\beta^{-1} C_{2}}{C_{1}} \Xi^{\prime}\left(S_{2}\right)=\frac{\beta^{-1} C_{2}}{C^{\star}} \Xi^{\prime}\left(S_{2}\right) \geq \frac{\Xi^{\prime}\left(S_{2}\right)}{\beta}>\frac{\Xi^{\prime}(0)}{\beta}>1 .
$$

Here, the final equality follows directly from (A1) and the restriction that $A^{H}>A^{L}$. Again, this contradicts the first-order condition for banks' profit maximization with $S_{2}>0$, so the supposition that $S_{1}=0$ and $S_{2}>0$ must be false.

Proposition A5. Suppose that $\Xi^{\prime}\left(C^{\star}\right)<\beta A^{H} / A^{L}$. For each

$$
B_{1} \in\left(0, \Xi^{-1}\left(\tilde{S}_{1}\right) \max \left\{1, \pi^{\star} / \Xi^{\prime}\left(\tilde{S}_{1}\right)\right\}\right],
$$

there exists a threshold $\bar{C}_{0}\left(\underline{B}_{1}\right)$ for $C_{0}$ such that

1. $\lim _{B \downarrow 0} \bar{C}_{0}(B)=\beta^{-1} C^{\star} \Xi^{\prime}(0)$,

2. $\bar{C}_{0}\left(B_{1}\right)$ is strictly increasing in $B_{1}$.

3. $\bar{C}_{0}\left(\Xi^{-1}\left(\tilde{S}_{1}\right) \max \left\{1, \pi^{\star} / \Xi^{\prime}\left(\tilde{S}_{1}\right)\right\}\right)=\tilde{C}_{0}$,

4. there is no equilibrium with $C_{0}<\bar{C}_{0}\left(B_{1}\right)$; and

5. any equilibrium of Proposition $A 2$ or $A 3$ with $C_{0} \geq \bar{C}_{0}\left(B_{1}\right)$ has a corresponding equilibrium with the given value of $B_{1}$ and the same sequences for $C_{t}$ and $N_{t}$;

Proof. Define

$$
B^{\star} \equiv P_{0}\left(\beta^{-1} C^{\star} \Xi^{\prime}\left(C^{\star}\right)\right) \Xi\left(C^{\star}\right) \max \left\{1, \pi^{\star} P_{0}\left(\beta^{-1} C^{\star} \Xi^{\prime}\left(C^{\star}\right)\right)^{\phi} / \Xi^{\prime}\left(\tilde{C}_{1}\right)\right\}
$$


and

$$
\Upsilon(C, B) \equiv\left\{\begin{aligned}
\frac{\beta C}{C^{\star}}-\Xi^{\prime}\left(\Xi^{-1}\left(\frac{B}{P_{0}(C) \max \left\{1, \pi^{\star} P_{0}(C)^{\phi} / \Xi^{\prime}\left(\tilde{C}_{1}\right)\right\}}\right)\right) & \text { if } B \leq B^{\star} \\
\theta(C)-\Xi^{-1}\left(\frac{B}{P_{0}(C) \max \left\{1, \pi^{\star} P_{0}(C)^{\phi} / \Xi^{\prime}\left(\tilde{C}_{1}\right)\right\}}\right) & \text { otherwise; }
\end{aligned}\right.
$$

where $\theta(C)$ definitionally satisfies $\beta^{-1} \theta(C) \Xi^{\prime}(\theta(C))=C$. Applying the implicit function theorem guarantees that $\theta(C)$ is strictly increasing in $C$, so it is straightforward to demonstrate that $\Upsilon(C, B)$ is also strictly increasing in $C$. Therefore, we can define $\bar{C}_{0}\left(B_{1}\right)$ implicitly with $\Upsilon\left(\bar{C}_{0}\left(B_{1}\right), B_{1}\right)=0$. Since $\Upsilon(C, B)$ is also strictly decreasing in $B, \bar{C}_{0}\left(B_{1}\right)$ is also decreasing in $B_{1}$ (establishing the second numbered result). The first and third numbered results can be verified by direct substitution into $\Upsilon(C, B)$.

For the fourth numbered result, suppose that there exists an equilibrium with $C_{0}<\bar{C}_{0}\left(B_{1}\right)$. This requires

$$
P_{0}<P_{0}\left(\bar{C}_{0}\left(B_{1}\right)\right) \text { and } 1+i_{0} \leq \max \left\{1, \pi^{\star} P_{0}\left(\bar{C}_{0}\left(B_{1}\right)\right)^{\phi} / \Xi^{\prime}\left(\tilde{C}_{1}\right)\right\}
$$

Since the real purchasing power of the fixed nominal bond issuance $B_{1}$ decreases with both $P_{0}$ and $i_{0}$, we can conclude that

$$
S_{1}>\Xi^{-1}\left(\frac{B_{1}}{P_{0}\left(\bar{C}_{0}\left(B_{1}\right)\right) \max \left\{1, \pi^{\star} P_{0}\left(\bar{C}_{0}\left(B_{1}\right)\right)^{\phi} / \Xi^{\prime}\left(\tilde{C}_{1}\right)\right\}}\right) .
$$

There are two cases to consider. If $B_{1} \leq B^{\star}$, then (A12), the definition of $\bar{C}_{0}(B)$, and the monotonicity of $\Xi^{\prime}(\cdot)$ together imply that

$$
\Xi^{\prime}\left(S_{1}\right)>\frac{\beta \bar{C}_{0}\left(B_{1}\right)}{C^{\star}}
$$

Banks' profit maximization and $S_{1}>0$ require that $\Xi^{\prime}\left(S_{1}\right)=\pi_{1} /\left(1+i_{0}\right)$; and the Euler equation for optimal household bond purchases requires that $\pi_{1} /\left(1+i_{0}\right)=$ $\beta C_{0} / C_{1}$. Therefore, we conclude that

$$
\frac{C_{0}}{C_{1}}>\frac{\bar{C}_{0}\left(B_{1}\right)}{C^{\star}}
$$

By assumption, $C_{0}<\bar{C}_{0}\left(B_{1}\right)$, so this requires that $C_{1}<C^{\star}$. However, the non- 
negativity constraint on labor supply in year 1 requires that $C_{1} \geq C^{\star}$ in any equilibrium. Therefore, the supposition of an equilibrium with $C_{0}<\bar{C}_{0}\left(B_{1}\right)$ must be incorrect.

Suppose instead that $B_{1}>B^{\star}$. There are two sub cases to consider. In the first, $C_{1} \leq C^{\star}$. The definitions of $B^{\star}$ and $\bar{C}_{0}\left(B_{1}\right)$ then give us

$$
S_{1}>\Xi^{-1}\left(\frac{B^{\star}}{P_{0}\left(\bar{C}_{0}\left(B^{\star}\right)\right) \max \left\{1, \pi^{\star} P_{0}\left(\bar{C}_{0}\left(B^{\star}\right)\right)^{\phi} / \Xi^{\prime}\left(\tilde{C}_{1}\right)\right.}\right)=C^{\star} \geq C_{1} .
$$

So the labor market clearing condition requires $S_{2}>0$. However, we know from Lemma 1 that $S_{2}=0$. In the second case, $C_{1}>C^{\star}$. The non-negativity condition on $N_{1}$ and Lemma 1 together require $S_{1}=C_{1}$, so $C_{1}=\theta\left(C_{0}\right)$. The monotonicity of $\theta(C),(\mathrm{A} 12)$, and the supposition that $C_{0}<\bar{C}_{0}\left(B_{1}\right)$ therefore give us

$$
S_{1}>\theta\left(\bar{C}_{0}\left(B_{1}\right)\right)>\theta\left(C_{0}\right)=C_{1}
$$

Again, this and the labor market clearing condition require $S_{2}>0$, which contradicts Lemma 1. Therefore, no equilibrium with $C_{0}<\bar{C}_{0}\left(B_{1}\right)$ exists.

The proof of the fifth numbered result exactly parallels exactly parallels the analogous proof for Proposition 6. 


\section{References}

Aruoba, S. B., P. Cuba-Borda, and F. Schorfheide (2016, January). Macroeconomic Dynamics Near the ZLB: A Tale of Two Countries.

Auerbach, A. J. and M. Obstfeld (2005, March). The Case for Open-Market Purchases in a Liquidity Trap. American Economic Review 95(1), 110-137.

Barro, R. (1974). Are Government Bonds Net Wealth? Journal of Political Economy 82(6), 1095-1117.

Bassetto, M. (2002, January). A Game-Theoretic View of the Fiscal Theory of the Price Level. Econometrica $70(6), 2167-2195$.

Benhabib, J., S. Schmitt-Grohé, and M. Uribe (2001, January). The Perils of Taylor Rules. Journal of Economic Theory 96(1), 40-69.

Berlin, A. and M. Z. Brettler (Eds.) (2004). The Jewish Study Bible. Oxford University Press.

Bernanke, B. and F. S. Mishkin (1997, April). Inflation Targeting: A New Framework for Monetary Policy? Journal of Economic Perspectives 11(2), 97-116.

Bhattari, S., G. B. Eggertsson, and B. Gafarov (2014, March). Time Consistency and the Duration of Government Debt: A Signalling Theory of Quantitative Easing.

Buera, F. and J. P. Nicolini (2014, November). Liquidity Traps and Monetary Policy: Managing a Credit Crunch;. Technical Report 2014-14, Federal Reserve Bank of Chicago Working Paper.

Calvo, G. A. (1983). Staggered Prices in a Utility-Maximizing Framework. Journal of Monetary Economics 12, 383-398.

Chen, H., V. Cúrdia, and A. Ferrero (2012, October). The Macroeconomic Effects of Large-scale Asset Purchase Programmes. The Economic Journal 122(564), F289-F315.

Christiano, L., M. Eichenbaum, and S. Rebelo (2011, February). When Is the Government Spending Multiplier Large? The Journal of Political Economy 119(1), $78-121$. 
Cochrane, J. (2013, October). The New-Keynesian Liquidity Trap.

Cochrane, J. H. (2011, June). Determinacy and Identification with Taylor Rules. The Journal of Political Economy 119(3), 565-615.

Cooper, R. and A. John (1988, August). Coordinating Coordination Failures in Keynesian Models. Quarterly Journal of Economics 103(3), 441-463.

Correia, I., E. Farhi, J. P. Nicolini, and P. Teles (2013, June). Unconventional Fiscal Policy at the Zero Bound. American Economic Review 103(4), 1172-1211.

Cúrdia, V. and M. Woodford (2011, January). The central-bank balance sheet as an instrument of monetary policy. Journal of Monetary Economics 58(1), 54-79.

Eggertsson, G. B. (2011, January). What Fiscal Policy Is Effective at Zero Interest Rates? NBER Macroeconomics Annual 25(1), 59-112.

Eggertsson, G. B. and P. R. Krugman (2012, August). Debt, Deleveraging, and the Liquidity Trap: A Fisher-Minsky-Koo Approach. Quarterly Journal of Economics 127(3), 1469-1513.

Eggertsson, G. B. and M. Woodford (2003). The Zero Bound on Interest Rates and Optimal Monetary Policy. Brookings Papers on Economic Activity 2003(1), 139-211.

Erceg, C. and J. Lindé (2014, January). Is there a Fiscal Free Lunch in a Liquidity Trap? Journal of the European Economic Association 12(1), 73-107.

Farmer, R. and P. Zabczyk (2016, March). The Theory of Unconventional Monetary Policy. Technical Report 22135, NBER.

Fisher, S. (1977, February). Long-Term Contracts, Rational Expectations, and the Optimal Money Supply Rule. Journal of Political Economy 85(1), 191-205.

Fornaro, L. (2013, May). Debt Deleveraging, Debt Relief and Liquidity Traps.

Gertler, M. and P. Karadi (2011, January). A model of unconventional monetary policy. Journal of Monetary Economics 58(1), 17-34. 
Korinek, A. (2016, April). Currency Wars or Efficient Spillovers? A General Theory of International Policy Cooperation. Technical report, Johns Hopkins University and NBER.

Krugman, P. R. (1998). It's Baaack: Japan's Slump and the Return of the Liquidity Trap. In Brookings Papers on Economic Activity, pp. 137-205.

Leeper, E. M. (1991). Equilibria under 'active' and 'passive' monetary and fiscal policies. Journal of Monetary Economics 27(1), 129-147.

Lucas, R. E. J. and L. A. Rapping (1969, September). Real Wages, Employment, and Inflation. Journal of Political Economy 77(5), 721-754.

Mertens, K. R. S. M. and M. O. Ravn (2014, October). Fiscal Policy in an Expectations-Driven Liquidity Trap. The Review of Economic Studies 81(4), $1637-1667$.

Rajan, R. (2014, April). Competitive Monetary Easing: Is it yesterday once more? (Remarks at the Brookings Institution, April 10, 2014).

Shleifer, A. (1986). Implementation Cycles. Journal of Political Economy 94(6), $1163-1190$.

Sims, C. A. (1994). A simple model for study of the determination of the price level and the interaction of monetary and fiscal policy. Economic Theory 4(3), 381-399.

Werning, I. (2012, October). Managing a Liquidity Trap: Monetary and Fiscal Policy. Technical report, MIT.

Woodford, M. (1994). Monetary policy and price level determinacy in a cash-inadvance economy. Economic Theory 4(3), 345-380. 